and Environment

Elsevier Editorial System(tm) for Building

Manuscript Draft

Manuscript Number: BAE-D-18-02763R1

Title: Investigating the behaviour of ASHRAE, Bedford, and Nicol thermal scales when translated into the Arabic language

Article Type: Original Research Paper

Keywords: Thermal scale; thermal comfort; translation influence;

Successive categories method; Arabic language; Oman

Corresponding Author: Ms. Hanan Al Khatri, MSC

Corresponding Author's Institution: University of Nottingham

First Author: Hanan Al Khatri, MSC

Order of Authors: Hanan Al Khatri, MSc; Mohamed B Gadi, Dr

Abstract: With the global spread of thermal comfort studies, thermal scales are translated into different languages to adapt local context in which the studies are applied. However, translating thermal comfort studies does not maintain the scales' behaviour associated with the original English versions. Behaviour differences include irregular categories' width, asymmetry, and deviation of the middle category centre from the centre of the thermal continuum. These differences have a negative influence on the results of thermal comfort studies and their accuracy. Applying the successive categories method, this paper explores the change in ASHRAE, Bedford, and Nicol scales' behaviour when translated into the Arabic language. The translated scales were integrated into questionnaires distributed among female high school students in Muscat, the capital city of Oman, as part of a larger survey that lasted for a whole year. The findings revealed the deviation of the translated scales from the original assumptions of the English versions. This included categories' irregular widths and asymmetry in addition to the deviation of the centre of the middle categories from the centre of the thermal continuum. Besides, it was found that both ASHRAE and Bedford scales covered different ranges on the thermal continuum, which questions their assumed equivalence. Based on these findings, the accuracy of the thermal comfort analysis is negatively affected. Considering the sensitivity of scales' behaviour to the used phrases, further explorations implementing the terms examined in this study are recommended. 


\title{
Investigating the behaviour of ASHRAE, Bedford, and Nicol thermal scales when translated into the Arabic language
}

\author{
Hanan Al-Khatri ${ }^{1,2, *}$ and Mohamed B. Gadi ${ }^{1}$ \\ ${ }^{1}$ Department of Architecture and Built Environment, Faculty of Engineering, University of Nottingham, Nottingham, NG7 2RD, \\ United Kingdom, E-mail: Hanan.Al-Khatri@nottingham.ac.uk (Hanan Al-Khatri), mohamed.gadi@nottingham.ac.uk (Mohamed \\ B. Gadi) \\ ${ }^{2}$ Department of Civil and Architectural Engineering, College of Engineering, Sultan Qaboos University, P.O. Box 33, Al-Khod, \\ Muscat, 123, Sultanate of Oman, E-mail: khatri@squ.edu.om \\ "Corresponding author, E-mail address: hanan.khatri@gmail.com, Tel: +44(0)1159515559, Fax: + 44(0)1159514115
}

\begin{abstract}
With the global spread of thermal comfort studies, thermal scales are translated into different languages to adapt local context in which the studies are applied. However, translating thermal comfort studies does not maintain the scales' behaviour associated with the original English versions. Behaviour differences include irregular categories' width, asymmetry, and deviation of the middle category centre from the centre of the thermal continuum. These differences have a negative influence on the results of thermal comfort studies and their accuracy. Applying the successive categories method, this paper explores the change in ASHRAE, Bedford, and Nicol scales' behaviour when translated into the Arabic language. The translated scales were integrated into questionnaires distributed among female high school students in Muscat, the capital city of Oman, as part of a larger survey that lasted for a whole year. The findings revealed the deviation of the translated scales from the original assumptions of the English versions. This included categories' irregular widths and asymmetry in addition to the deviation of the centre of the middle categories from the centre of the thermal continuum. Besides, it was found that both ASHRAE and Bedford scales covered different ranges on the thermal continuum, which questions their assumed equivalence. Based on these findings, the accuracy of the thermal comfort analysis is negatively affected. Considering the sensitivity of scales' behaviour to the used phrases, further explorations implementing the terms examined in this study are recommended.
\end{abstract}

Keywords: Thermal scale; thermal comfort; translation influence; Successive categories method; Arabic language; Oman

\section{Introduction}

Satisfying thermal comfort requirements of buildings' occupants is a considerable challenge for two reasons. First, these requirements are generally an important consumer of energy in buildings $[1,2]$. Second, thermal comfort has a subjective nature that requires a good understanding of users' thermal demands [3]. With the aim of contributing towards this understanding, researchers usually conduct thermal comfort studies inside real buildings. In these studies, they often distribute questionnaires that involve using thermal scales as a major tool to seek participants' thermal sensations. Voting a thermal sensation requires the subjects to feel, evaluate, and express their thermal states using thermal scales. It is possible to consider these word-based scales as numerical measures of subjective 
experience as the thermal votes obtained from the distributed questionnaires are usually expressed in numerical form for analysis purposes.

Among several sensation scales found in the literature [4,5], ASHRAE and Bedford scales are widely used. Both scales consist of seven categories that are usually converted during analysis into a numerical range from $(-3)$ to $(+3)$ as follows:

- ASHRAE scale: cold (-3), cool (-2), slightly cool $(-1)$, neutral $(0)$, slightly warm $(+1)$, warm (+2), hot $(+3)$

- Bedford scale: much too cool (-3), too cool (-2), comfortably cool (-1), comfortable neither warm nor cool $(0)$, comfortably warm $(+1)$, too warm $(+2)$, much too warm $(+3)$

Moreover, thermal preference scales are mainly introduced to overcome possible confusion between neutrality and culturally desirable sensations [6-8]. McIntyre, Nicol, and a modified version of ASHRAE sensation scales are widely used to report thermal preferences. These scales have three, five, and seven categories respectively as follows:

- McIntyre scale: warmer (-1), no change (0), cooler $(+1)$

- Nicol scale: much warmer (-2), a bit warmer (-1), no change (0), a bit cooler (+1), much cooler

- ASHRAE scale: much warmer (-3), warmer (-2), slightly warmer (-1), no change (0), slightly cooler $(+1)$, cooler $(+2)$, much cooler $(+3)$

\subsection{Challenges in using thermal sensation scales}

Despite the continuous implementation of thermal sensation scales, there are some challenges in applying them. These challenges may be classified into those related to scales in their English or original form and those related to the translated versions. The reasons for these challenges include the difference between neutrality and comfort, the effect of the climatic and cultural background, and participants' difference in realising thermal sensations and their distribution on the thermal continuum [8]. Additional reasons include the variations that result from translation. Translating thermal scales has a positive impact on the participation rate as it adapts the scales to the local context $[9,10]$. However, deviations from the original English scales exist due to the absence of equivalent sensations in the translated languages or the difference in the impressions associated with these sensations [11].

Examples of such challenges include the statistical evidence on the different interpretations of ASHRAE sensation scale [7]. Another is the use of a numerical system to describe a psychological 
experience [6]. Some studies attempt to overcome this via using continuous scales like the study of [12]. According to McIntyre cited in [4], employing continuous scales may reflect accurate sensations, especially under slight or slow variations of temperature. However, such scales may be impractical, introduce errors [6], and reduce the results' accuracy [13].

Regardless of the widely accepted assumption of exchangeable use of ASHRAE and Bedford scales, the former assumes that thermal comfort is equivalent to any sensation from the central categories (i.e. slightly cool, neutral, slightly warm), whereas the latter integrates (comfort) in its categories. The inequality between neutrality and comfort was proven statistically in a study that requested the subjects to identify thermal comfort along ASHRAE scale. The findings indicated that neutrality was cooler than comfort for the involved participants. It is worth mentioning that this study was conducted in winter with a majority of English participants [8]. A similar result was found in a recent study conducted for a whole year among Eastern Arabs; yet, neutrality was warmer than comfort, which can be justified by the influence of the climatic background of the participants [14]. Furthermore, some studies highlighted few discrepancies in the exchangeable use of ASHRAE and Bedford scales $[9,15,16]$. For instance, accepting thermal surroundings was higher by about $20 \%$ using Bedford scale compared with ASHRAE in a study that took place in a high school in Singapore. In this study, thermal acceptability and the votes in the central categories were assumed to be equivalent [15]. However, scales' difference may be due to their use in that study as ASHRAE scale was applied to evaluate ambience temperature and Bedford scale was applied to evaluate thermal sensation.

In another study that compared Indonesian translations of both scales, variations in votes' distribution were revealed. In specific, ASHRAE votes distributed relatively evenly, whereas Bedford votes clustered in central categories. Accordingly, the researchers concluded that ASHRAE scale had a better behaviour [17], which may justify their use of ASHRAE data in their analysis. However, applying successive categories method indicated that Bedford scale behaved better [18] and, thus, computing neutral temperature using its data may lead to conclusions with better accuracy. Additionally, a similar clustering of thermal votes using Bedford scale in the central categories compared with ASHRAE scale was reported in [19]. The clustering behaviour of Bedford votes may indicate a lack of sensitivity [5] and the reasons for this pattern of distribution are not clearly known. It is probably due to people variation in their perception to thermal ambience or their interpretation of thermal scales [4]. 
Another possible reason is the integration of (comfort) in the central categories; usually, people tend to keep themselves thermally comfortable as indicated by the adaptive principle.

Considering the challenges associated with translation, the translated thermal scales deviates from the assumptions of the English scales and, consequently, changes their behaviour. Examples of these deviations include the divergence of the middle category centre from (zero), unequal width of categories, and asymmetrical categories. Such changes were reported when translating ASHRAE and Nicol scales into French, Swedish, Portuguese, and Greek languages $[11,18]$. Similar changes in scales' behaviour were revealed in a study that translated both scales into Japanese and compared their behaviour with a Japanese scale $[18,20]$. Likewise, comparing the translated sensation phrases used in some Arabic studies of thermal comfort revealed that the translated phrases associated possibly desirable impressions to sensations outside the three central categories. Besides, the translated scales covered different ranges on the thermal continuum compared with the ASHRAE or Bedford 7-points scales [14].

It should be mentioned that these variations in scales' behaviour are not attributed to the translation effect solely. Climatic background and acclimatisation can be considered as other contributors [18]. In this regard, a recent study investigated the climatic effect on thermal responses and terms of Bangladeshi and Japanese participants. A translated version of ASHRAE 11-point scale was integrated in the distributed questionnaire besides imaginary thermal scenarios at which participants should describe their sensations. Significant variations in thermal sensations were reported, which emphasises the impact of the climatic background [21].

\subsection{Thermal scales in literature}

This section presents the literature concerned with thermal scales to highlight the lack of research regarding the behaviour of translated thermal scales applying the successive categories method, which is the focus of this paper. Indeed, there are few studies concerned with thermal scales in general [22] despite their wide applications in thermal comfort studies. Reviewing the literature revealed recent investigations regarding different aspects of thermal scales including people interpretation of thermal scales $[8,11,14,22,23]$, examining the scales' assumptions $[4,8,14]$, the relationship between comfort and neutrality $[8,11,14,24]$, uncertainty of thermal comfort measurements related to thermal scales and survey protocol [13], comparing different thermal scales $[5,25]$, and proposing a new preference scale [26]. As noted, the majority of these studies were published during the last year. 
People vary in their interpretation of thermal scales, which was noted in studies like $[4,8,14]$. These variations include the differentiation between phrases, identification of the phrases' positions and distances, and the concepts associated with each sensation. For instance, a relatively weak differentiation between (slightly cool) and (cool) as well as between (slightly warm) and (warm) were revealed among Eastern Arab students. Linking this to the participants' climatic background highlights the importance of considering it when translating thermal scales and defining thermal comfort zone [14]. People's variations in identifying the positions of and the distances between ASHRAE sensation phrases were not random from a statistical point of view. This implies that comfort is not necessarily related to the three central thermal sensations as widely assumed. Interestingly, grouping participants based on these variations can increase the prediction accuracy of thermal comfort models [22]. In this regard, the generalisation of thermal votes was questioned based on the different conceptions and experiences associated with the sensation phrases of ASHRAE scale [23].

Regarding the scales' assumptions, it was revealed that the assumptions of equal categories' width and comfort range may not be valid and the used scale type (ordinal or continuous) affects survey results. This implies that temperature steps, which are the temperature changes required to move by one thermal sensation, are not necessarily uniform [4]. However, these findings may require further examination considering the sample size of the experiment.

Moreover, the degree of which thermal neutrality can be considered as an indication of thermal comfort was investigated by a recent study conducted in Norwegian and British offices. The study highlighted that ASHRAE definition of thermal comfort does not refer to neutrality; yet, several studies of thermal comfort considered them as equivalents. The findings confirm the difference between comfort and neutrality as around $36 \%$ and $60 \%$ of the participants in the questionnaires and interviews respectively wanted different sensations than neutrality [24], which was highlighted in other studies $[8,11,14]$.

Additionally, the effect of the survey protocol, including participants' number and votes per participant number, and questionnaire characteristics, including scale type (continuous or discrete) and choices' number, on the intra-individual and subjective measurement uncertainty was investigated. The intraindividual variation refers to the change in the one participant votes under similar thermal environments. It is recommended to use discrete thermal scales of no more than 7-points to reduce 
the intra-individual variations. Increasing the number of votes per person has a positive influence on the subjective measurement uncertainty and a recommended number is 40 person-votes [13]. Some researchers investigated the assumption of equivalence between the different thermal scales $[5,25]$. The former study highlighted the absence of a well-established base to compare thermal sensation scales. The researchers suggested considering the scales with an equal number of categories equivalent although they differ in the associated phrases. Besides, they suggested unifying the length of scales with different categories number by categories' redistribution [25]. Obviously, this attempt involves changing the original widths of categories besides assuming equality between extreme sensations. It is worth to mention that such equality lacks evidence. Moreover, exploring scales' behaviour, by applying the successive categories method, may reveal some variations in the scales' behaviour despite their equal number of categories. In another study, the application of a categorical scale, a visual analogue scale, and a combined scale with visual analogue and categorical features was explored by integrating them in a questionnaire besides an accompanied experiment. The scales were translated into Korean and Japanese to suit participants' mother tongue. It was found that verbal scales expressed thermal sensations more precisely and exhibited higher correlations with indoor air temperature compared with visual scales [5].

Furthermore, an application was designed to collect users' thermal preference votes promptly using their smartphones or computers. The integrated scale implemented ASHRAE phrases except (slightly cool) and (slightly warm). The results indicated the application success in fulfilling its purpose.

Besides, the accompanied field study revealed that preference votes were mostly influenced by the ambient temperature [26]. It is noteworthy that exploring the properties of the used scale was out of scope in that study.

\subsection{Research aim}

Translated thermal scales are supposed to maintain the assumptions of their English versions (original version). However, maintaining a similar behaviour is affected by the characteristics of the translated language and the accuracy of the translation. Any deviation from the scales' original assumptions has a negative influence on the results of the thermal comfort studies. For instance, the irregularity in categories' widths had a negative effect on the results of the regression analysis. This analysis is widely applied in the thermal comfort studies and it requires equal intervals of both the dependent and independent variables [6]. The paper at hand attempts to explore the behaviour of ASHRAE, Bedford, and Nicol scales when translated into the Arabic language applying the 
successive categories method; in particular, it investigates to which extent do the translated scales maintain equal distances between categories, symmetry around the middle category, and the coincidence between the middle category and the centre of the thermal continuum. These assumptions were investigated in previous studies using free positioning only where the participants were requested to distribute thermal phrases on the thermal continuum $[4,8,14]$. Up to the knowledge level of the authors, this study is the first concerning thermal scales translated into the Arabic language.

In this research, the investigated phrases covered a range on the continuum similar to that covered by the internationally agreed Arabic version, which is available in [27]. However, the phrases of this version were not applied in the current research because they are not commonly used in the Eastern Arabic region that includes Oman, where the investigation was applied. It is worth to mention that the Arabic language has different dialects and the used vocabulary is affected by the geographical origin of the speaker [28].

As noted from sections (1.1.) and (1.2.), there is a lack of research regarding the behaviour of translated thermal scales, especially when translated into the Arabic language, despite the recent interest in studying thermal scales. Additionally, few thermal comfort studies are generally conducted in the Arabic region regardless of its extreme climatic conditions and the high dependence on nonrenewable energy in satisfying thermal comfort demands. It is hoped that this study will contribute towards filling this gap of knowledge and encourage other researchers to carry out more thermal comfort research in the Arabic region as well as to apply the successive categories method to investigate the thermal scales' behaviour.

\section{Methodology}

The investigated scales in this study (i.e. ASHRAE, Bedford, and Nicol) were integrated into two questionnaires distributed among high school students as part of a thermal survey that was conducted for a whole academic year. The successive categories method was applied to compare the scales' behaviour and examine their stability during the survey. Widely used in psychometric studies, the method is recently implemented to explore the properties of the thermal scales by defining the actual width of the scales' categories as perceived by the participants. This enables comparing the categories' widths and their relative positions and, thus, exploring the scales' behaviour. To apply the method, the compared scales should be derived from the same survey, i.e. the same subjects and 
similar thermal conditions. Although the method may not be accurate for extreme categories (i.e. cold and hot in ASHRAE sensation scale for instance), the formed conclusions are generally not influenced as usually very few votes fall in those categories [18].

In general, comparing the behaviour of thermal scales includes making assumptions regarding the participants' response or regarding the thermal conditions. For instance, some studies assumed that different participants, answering questionnaires with different scales, have almost similar responses under identical conditions like [5]. Other attempts like [15] involved distributing a questionnaire with more than one thermal sensation scale to the same participants. Neither approach is theoretically correct because of the participants' change in the former study and the time lag in the latter.

Moreover, distributing more than one sensation scale within the same questionnaire increases the risk of subjects' boredom due to questions' repetition. In the research reported in this paper, the same participants answered questionnaires that integrated the explored scales separated by time lag under similar thermal conditions.

\subsection{Data}

The data analysed in this paper are part of a thermal survey conducted in Muscat, the capital city of the Sultanate of Oman. Five female high schools were visited twice in summer and three of them were visited twice in winter. Two schools were excluded from winter study because of unforeseen problems. In total, 15 and 9 classrooms were visited in summer and winter respectively. In each visit, the classrooms' objective data represented in the indoor air temperature, globe temperature, relative humidity, and air velocity were collected for a whole school day. Besides, a questionnaire was distributed among the students once towards the end of the fourth, fifth, or sixth class. The questionnaire integrated a translated version of ASHRAE or Bedford sensation scale, whereas Nicol preference scale was integrated into all questionnaires' versions. The sequence of distributing the questionnaires is illustrated in Figure 1. Besides, the translated head questions and the translated phrases of scales' categories are displayed in Table 1. These translations are included because the scales' behaviour depends on the used terms, i.e. it is possible for two scales translated into one language using different terms to behave differently [18]. 


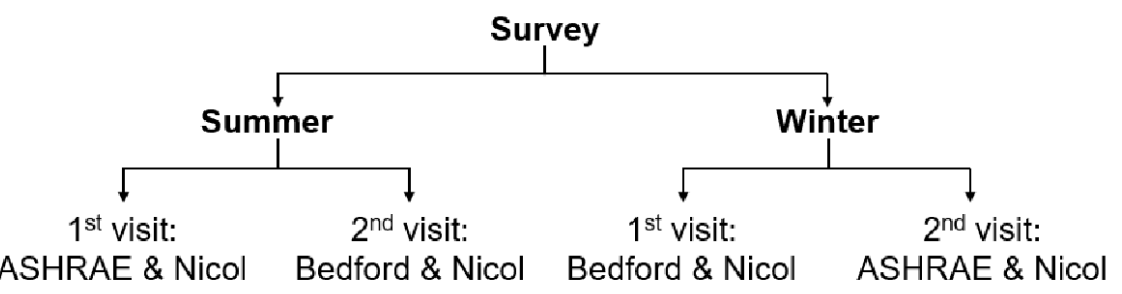

Figure 1: Sequence of questionnaires' distribution

\begin{tabular}{|c|c|c|c|c|c|}
\hline \multicolumn{2}{|c|}{ ASHRAE } & \multicolumn{2}{|c|}{ Bedford } & \multicolumn{2}{|c|}{ Nicol } \\
\hline English & Arabic & English & Arabic & English & Arabic \\
\hline Currently, I feel: & حاليا، أشعر بـ: & Currently, I feel: & حاليا، أشعر ب-: & $\begin{array}{l}\text { Currently, I would } \\
\text { prefer to be: }\end{array}$ & حاليا، أريد أن أكون: \\
\hline Cold & باردة جدا & Much too cool & باردة جدا & Much warmer & أسخن كثير ا \\
\hline Cool & باردة & Too cool & باردة & A bit warmer & أسخن قليلا \\
\hline Slightly cool & باردة قليلا & Comfortably cool & باردة لكن مرتاحة & No change & لا تغيير \\
\hline Neutral & معتدلة & $\begin{array}{l}\text { Comfortable, neither } \\
\text { cool nor warm }\end{array}$ & مرتاحة لا باردة و لا & A bit cooler & أبرد قليلا \\
\hline Slightly warm & ساخنة قليلا & Comfortably warm & ساخنة لكن مرتاحة & Much cooler & أبرد كثير ا \\
\hline Warm & ساخنة & Too warm & ساخنة & & \\
\hline Hot & ساخنة جدا & Much too warm & ساخنة جدا & & \\
\hline
\end{tabular}

As noted from Table 1, the non-central categories of ASHRAE and Bedford scales (i.e. categories -3, $-2,+2$, and +3 ) were translated to identical Arabic phrases. This allows exploring the stability of these categories' behaviour besides exploring the translation impact on comfort range (i.e. the three central categories). It is noteworthy that both (cool) and (cold) words are often translated into one term in the Arabic language. To distinguish between the two sensations, the latter was literally translated as (very cold). Moreover, the literal translation of (warm) may be a desirable sensation especially in winter; thus, it was translated to a phrase that means (hot) to convey the negative impression of this category. This led to translating (hot) as (very hot), which additionally maintained the scales' symmetry. Consequently, the thermal ranges covered by the two scales' versions (i.e. English and Arabic) are different; yet, this change is acceptable as it is part of adapting scales to the local context. In the Smart Controls and Thermal Comfort (SCAT) project, the French, Greek, and Portuguese versions of the scale were manipulated in a similar manner [11]. Despite this difference in the thermal ranges, both English and Arabic scales' versions are assumed to maintain similar uniform gaps between the consecutive sensations.

\subsection{Participants}

The research presented in this paper is a part of a larger survey that requires participants with a certain level of English language capacity. The participated students spent at least nine years studying English as a second language and, thus, had acquired a suitable level of the language for the survey. However, the genders separation of the Omani educational system, the conservative 
nature of the Omani society, and the lack of resources to recruit male research assistants to distribute the questionnaires among male participants can create a selection bias. Consequently, votes' clustering in some categories may occur as noted in previous studies [29-37] that explored the difference in thermal responses among different genders. This votes' clustering may have an influence on the categories' boundaries. However, the nature of the exploration reported in this paper does not 'really' require a representative sample as stated by [7]: "For an exploration of the interior dynamic of the scale, it was not necessary to choose respondents by representative sampling, nor thermal environments strictly representative of the respondents' thermal experience, and nor was comprehensive measurement of the thermal environment required."

\subsection{Site description and selected schools} Located at $23.61^{\circ} \mathrm{N}$ longitude and $58.54^{\circ} \mathrm{E}$ latitude, Muscat is the capital city of Sultanate of Oman. According to Koppen-Geiger climate classification, the city is located within a desert hot arid region. However, its mountainous nature and proximity from the Indian Ocean changed that climate to a hot and humid one [38-40]. It is possible to distinguish two climatically distinctive periods in the city. The first starts in April and extends to October and it forms the hot humid period. Maximum air temperature reaches $45^{\circ} \mathrm{C}$ in May and the mean extends from $30{ }^{\circ} \mathrm{C}$ in April and October to $35^{\circ} \mathrm{C}$ in June. Mean relative humidity extends between $42 \%$ and $74 \%$ in May and August respectively. The other period is relatively cooler as mean air temperature extends between $21^{\circ} \mathrm{C}$ in January and $26^{\circ} \mathrm{C}$ in November and mean relative humidity ranges from $57 \%$ to $66 \%$ in March and December respectively. It is noteworthy that temperature drop at night is minor in Muscat because the basaltic rock formations in the city release the heat absorbed during daytime causing continuous high temperatures and relative humidity [39].

There are 10 governmental high schools for female students in Muscat city. Two of these schools are located in rural areas, which make their participation in the research inconvenient. Thus, a primary list of the schools consisted of a convenient sample that included eight governmental schools. They were classified into four groups based on their architectural style, namely courtyards, clustered courtyards, linear form, and a combination of courtyards and wings. One school from each group was selected to participate in the survey. A fifth school was investigated because it has three floors, unlike the other schools that have two floors only. It is worth mentioning that private schools were excluded from this investigation due to the limited number of students in each classroom. 


\section{Results and discussion}

Recalling that applying successive categories method requires deriving the explored scales from one thermal survey, the thermal environments of the participated classrooms were investigated to ensure that the students were subjected to similar conditions. It was found that some classrooms were thermally different. Therefore, all questionnaires from these classrooms were excluded from the analysis below. Discussing the thermal conditions of the investigated classrooms is out of this paper's scope. Besides, the questionnaires returned from students who were involved in physical education classes before participating in the survey were excluded. As a result, 333 and 349 copies of ASHRAE and Bedford questionnaires respectively of summer study were included in the analysis. The corresponding copies of winter study were 209 and 194.

The successive categories method was applied to determine the probits that represent the categories upper limits. To compute the probits, the students' votes in each category were determined and the cumulative numbers of votes were calculated. The cumulative proportion of each category was computed by dividing the cumulative number of votes in that category by the total number of votes. The cumulative proportions were then transformed into probits using the cumulative normal distribution of unit standard deviation on the psychological continuum. The application of the successive categories method in the thermal comfort field is comprehensively illustrated in chapter (18) of Adaptive Thermal Comfort: Foundations and Analysis book [18].

The computed probits of thermal scales in summer are displayed in Table 2 and those in winter are presented in Table 3. To visualise the findings, graphical representations of the tables are demonstrated in Figure 2 for the former and in Figure 3 for the latter. Based on these tables and figures, it is possible to compare the translated scales and investigate their behaviour through comparison with the original assumptions of the English scales. In particular, the categories' width and symmetry can be obtained from these figures besides the coincidence between the scales' middle categories and the thermal continuum centre. More details are discussed in the following sections. 


\begin{tabular}{|c|c|c|c|c|c|c|}
\hline \multirow[b]{2}{*}{ Category } & \multicolumn{3}{|c|}{ ASHRAE, N = 333} & \multicolumn{3}{|c|}{ Bedford, N = 349} \\
\hline & Cum. Prop. & Probit & SE & Cum. Prop. & Probit & SE \\
\hline-3 & 0.009 & -2.37 & 0.173 & 0.009 & -2.38 & 0.172 \\
\hline-2 & 0.027 & -1.93 & 0.126 & 0.072 & -1.46 & 0.094 \\
\hline-1 & 0.168 & -0.96 & 0.079 & 0.269 & -0.61 & 0.070 \\
\hline 0 & 0.661 & 0.41 & 0.072 & 0.771 & 0.74 & 0.076 \\
\hline+1 & 0.877 & 1.16 & 0.093 & 0.880 & 1.17 & 0.092 \\
\hline+2 & 0.985 & 2.17 & 0.224 & 0.989 & 2.27 & 0.252 \\
\hline \multirow[t]{2}{*}{+3} & 1.000 & - & - & 1.000 & - & - \\
\hline & \multicolumn{3}{|c|}{ Nicol (ASHRAE), N = 333} & \multicolumn{3}{|c|}{ Nicol (Bedford), N = 349} \\
\hline-2 & 0.000 & - & - & 0.006 & -2.53 & 0.193 \\
\hline-1 & 0.111 & -1.22 & 0.086 & 0.135 & -1.10 & 0.081 \\
\hline 0 & 0.351 & -0.38 & 0.070 & 0.507 & 0.02 & 0.067 \\
\hline+1 & 0.814 & 0.89 & 0.083 & 0.917 & 1.38 & 0.104 \\
\hline+2 & 1.000 & - & - & 1.000 & - & - \\
\hline \multicolumn{7}{|c|}{ Table 2: Cumulative proportions, probits, and standard errors of thermal categories (summer) } \\
\hline & \multicolumn{3}{|c|}{ Bedford, $\mathbf{N}=194$} & \multicolumn{3}{|c|}{ ASHRAE, N = 209} \\
\hline Category & Cum. Prop. & Probit & SE & Cum. Prop. & Probit & SE \\
\hline-3 & 0.015 & -2.16 & 0.186 & 0.010 & -2.34 & 0.206 \\
\hline-2 & 0.041 & -1.74 & 0.143 & 0.053 & -1.62 & 0.130 \\
\hline-1 & 0.222 & -0.77 & 0.097 & 0.124 & -1.15 & 0.105 \\
\hline 0 & 0.711 & 0.56 & 0.098 & 0.612 & 0.29 & 0.089 \\
\hline+1 & 0.820 & 0.91 & 0.111 & 0.828 & 0.95 & 0.108 \\
\hline+2 & 0.979 & 2.04 & 0.270 & 0.952 & 1.67 & 0.171 \\
\hline \multirow[t]{2}{*}{+3} & 1.000 & - & - & 1.000 & - & - \\
\hline & \multicolumn{3}{|c|}{ Nicol (Bedford), N = 194} & \multicolumn{3}{|c|}{ Nicol (ASHRAE), N = 209} \\
\hline-2 & 0.005 & -2.57 & 0.250 & 0.005 & -2.59 & 0.248 \\
\hline-1 & 0.088 & -1.36 & 0.118 & 0.062 & -1.54 & 0.124 \\
\hline 0 & 0.448 & -0.13 & 0.090 & 0.344 & -0.40 & 0.088 \\
\hline+1 & 0.871 & 1.13 & 0.123 & 0.804 & 0.86 & 0.104 \\
\hline+2 & 1.000 & - & - & 1.000 & - & - \\
\hline
\end{tabular}

Table 3: Cumulative proportions, probits, and standard errors of thermal categories (winter)

Nicol (Bedford)

Nicol (ASHRAE)

Bedford

ASHRAE

\begin{tabular}{l|l|c|c|c}
\hline $\mathrm{mw}$ & $\mathrm{abw}$ & $\mathrm{nc}$ & $\mathrm{abc}$ & $\mathrm{mc}$ \\
\hline \multicolumn{6}{c}{} \\
\hline $\mathrm{mw}$ & $\mathrm{abw}$ & $\mathrm{nc}$ & $\mathrm{abc}$ \\
\hline
\end{tabular}

\begin{tabular}{c|c|c|c|c|c|c|c|c}
\hline $\mathrm{mtc}$ & $\mathrm{tc}$ & $\mathrm{cc}$ & $\mathrm{c}$ & $\mathrm{cw}$ & $\mathrm{tw}$ & $\mathrm{mtw}$ \\
\hline \multicolumn{10}{c}{} \\
\hline $\mathrm{cd}$ & $\mathrm{c}$ & $\mathrm{sc}$ & $\mathrm{n}$ & $\mathrm{sw}$ & $\mathrm{w}$ & $\mathrm{h}$ \\
\hline \multicolumn{1}{c}{} \\
\hline-3 & -2 & -1 & 0 & 1 & 2 & 3
\end{tabular}

Key:

ASHRAE: $c d=$ Cold,$c l=C$ cool, $s c=$ Slightly cool, $\mathrm{n}=$ Neutral, $s w=$ Slightly warm, $\mathrm{w}=$ Warm, $\mathrm{h}=\mathrm{Hot}$

Bedford: $\mathrm{mtc}=$ Much too cool, tc $=$ Too cool, $\mathrm{cc}=$ Comfortably cool, $\mathrm{c}=$ Comfortable neither warm nor cool

$\mathrm{cW}=$ Comfortably warm, $\mathrm{tw}=$ Too warm, $\mathrm{mtw}=$ Much too warm

Nicol: $\mathrm{mw}=$ Much warmer, $\mathrm{abw}=\mathrm{A}$ bit wamer, $\mathrm{nc}=$ no change, $\mathrm{abc}=\mathrm{A}$ bit cooler, $\mathrm{mc}=$ Much cooler

Figure 2: Comparing thermal categories' widths of ASHRAE, Bedford, and Nicol scales in summer

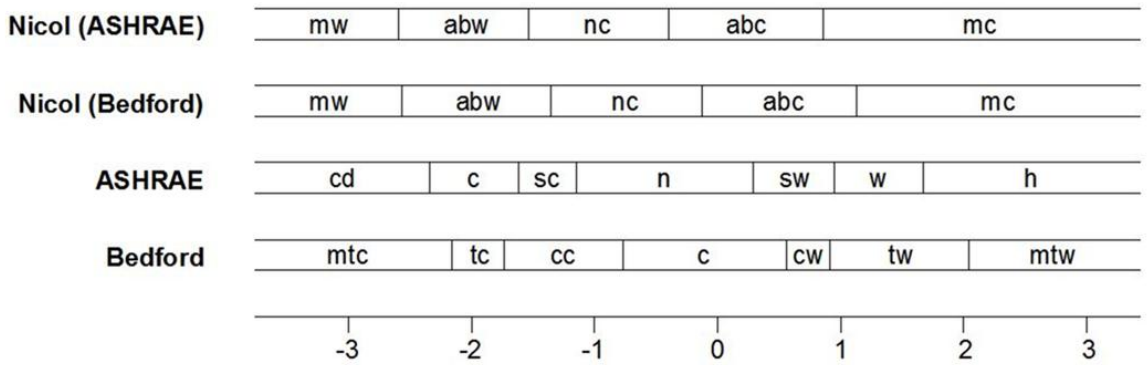

Key:

ASHRAE: $c d=$ Cold,$c l=$ Cool,$s c=$ Slightly cool $n=$ Neutral, $s w=$ Slightly warm, $w=$ Warm, $h=$ Hot Bedford: $\mathrm{mtc}=$ Much too cool, $\mathrm{tc}=$ Too cool, $\mathrm{cc}=$ Comfortably cool, $\mathrm{c}=$ Comfortable neither warm nor cool, $\mathrm{cw}=$ Comfortably warm, $\mathrm{tw}=$ Too warm, $\mathrm{mtw}=$ Much too warm

Nicol: $\mathrm{mw}=$ Much wamer, $\mathrm{abw}=\mathrm{A}$ bit warmer, $\mathrm{nc}=$ no change, $\mathrm{abc}=\mathrm{A}$ bit cooler, $\mathrm{mc}=$ Much coole

Figure 3: Comparing thermal categories' widths of Bedford, ASHRAE, and Nicol scales in winter 


\subsection{Categories' widths}

In the following sections, the categories' widths are compared at three levels as illustrated in Figure 4. In the first level, the categories' widths are compared within each scale. In the second, the compared categories are from different scales. This includes comparing widths of ASHRAE and Bedford categories besides comparing them with those of Nicol scale. Considering the third level, it compares the widths of the same categories from different questionnaires within the same survey.

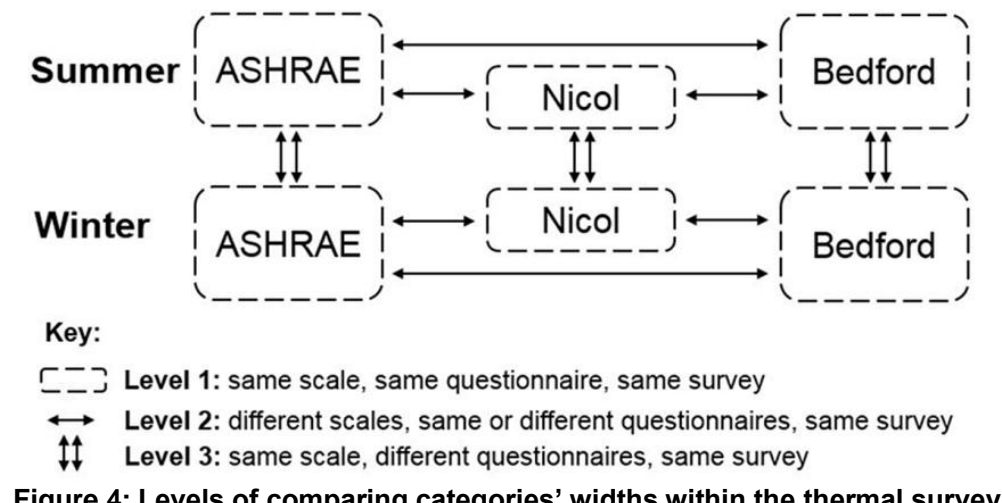

3.1.1. Comparing categories' widths within each scale

As noted in Figure 2 and Figure 3, the widths of sensation categories were irregular in both seasons.

Accordingly, moving between categories required unequal temperature steps besides applying regression analysis, to compute the neutral temperature for instance, may not be totally accurate as the equation is negatively influenced by these irregularities. The middle categories are the widest, which indicates that wide ranges of temperature are considered (neutral) or (comfortable) for the investigated students. In both seasons, (comfortably warm) category was noticeably narrow perhaps for climatic and cultural reasons as it is possible that the students found it difficult to combine comfort with a warm sensation. Regarding Nicol scale, roughly uniform temperature differences were required to move between preference categories due to their relatively equal widths. It is noteworthy that (a bit cooler) category during ASHRAE questionnaire of summer study had no defined width owing to votes' absence in (much cooler) category. Similarly, end categories of all scales had no defined widths.

3.1.2. Comparing categories' widths from different scales

The thermal continuum ranges covered by sensation categories were almost similar in summer and slightly different in winter as observed in Figure 2 and Figure 3 respectively. In both seasons, (neutral) category was shifted to the cool side of the continuum, whereas (comfortable) was almost centred on the continuum centre (i.e. zero point) regardless of their assumed equivalence. Although an identical 
Arabic phrase was used for both (cool) and (too cool), they had noticeably different widths in both seasons. This indicates that translation is not the only factor that determines categories' widths. Considering Nicol scale, (neutral) and (comfortable) sensations were preferred for the investigated students as they contained the centre of (no change) category in both seasons.

\subsection{Middle categories' shift from the thermal continuum centre}

The distances between the thermal continuum centre (i.e. zero point) and the centres of (neutral) and (comfortable) categories were determined. Accordingly, the behaviour of Bedford scale in both seasons seems to be relatively better owing to the closeness between the median sensation (i.e. zero point) and the centre of (comfortable) category as demonstrated in Figure 2 and Figure 3 . The reason is possibly related to the used phrase that emphasised the absence of (cool) or (warm) sensations. Besides, it seems that Bedford scale exhibited a better response to the season change. This is because the centre of its middle category moved from the warm side in summer to the cool side in winter. Additionally, the spread of air conditioning systems in Omani buildings $[41,42]$ may have an influence on the investigated students as (neutral) was shifted to the cool side of the continuum in both seasons. Supporting this influence is the shift of (no change) preference to the cool side of the continuum. It may worth mentioning that the literal translation of the phrase used for (neutral) means (moderate) or (mild).

\subsection{Categories' symmetry}

With respect to the middle category centre, the categories of ASHRAE scale seem to be more symmetrical compared with those of Bedford scale as observed in Figure 2 and Figure 3. The general asymmetry of the Bedford scale may be related to integrating (comfort) in its central categories; it is possible that the students found it difficult to feel comfortable while feeling warm as in (comfortably warm) category owing to their climatic background. It is noteworthy that the votes of (slightly warm) were almost double those of (comfortably warm) in each season. Additionally, the categories of Nicol scale were relatively symmetrical around its central category in both seasons indicating good behaviour.

\subsection{Accuracy of categories' boundaries}

To determine the accuracy of the categories' limits, it is crucial to ensure the independence of the involved data [18]. Considering the research at hand, the analysed data were truly independent as each student provided one vote in each questionnaire. The computed standard errors of summer and winter studies are presented in Table 2 and Table 3 respectively. The standard errors of Bedford 
scale categories were marginally smaller in summer, whereas those of ASHRAE scale were relatively smaller in winter. This is mainly related to the sample size and was reflected by the associated Nicol scales. Indeed, the influence of sample size on the accuracy is obvious comparing the standard errors of each scale in summer with those in winter. Likewise, the standard errors of the central categories in all scales were comparatively smaller mainly owing to the usual clustering of votes in the central categories [18].

It should be mentioned that the standard errors in both seasons were generally large. Consequently, the calculated widths of categories may be considered as approximate estimations. It is possible that these errors reflected the students' doubt in using the investigated scales, which may be reasonable considering that it was the first time for almost all of the students to answer a questionnaire.

\subsection{Stability of sensation scales}

The widths of sensation categories were different in the explored seasons as observed in Figure 2 and Figure 3. To investigate the stability of the scales' behaviour, the correlation between categories' widths in summer and winter are plotted in Figure 5. Ideally, the correlation coefficient should be unity. Nevertheless, this is highly unlikely owing to the seasonal thermal variations [18]. In ASHRAE scale, the correlation coefficient was high $(r=0.995)$; however, it was negligibly higher in Bedford scale $(r=$ 0.996). Therefore, it seems that both scales maintained their behaviour throughout the survey period.

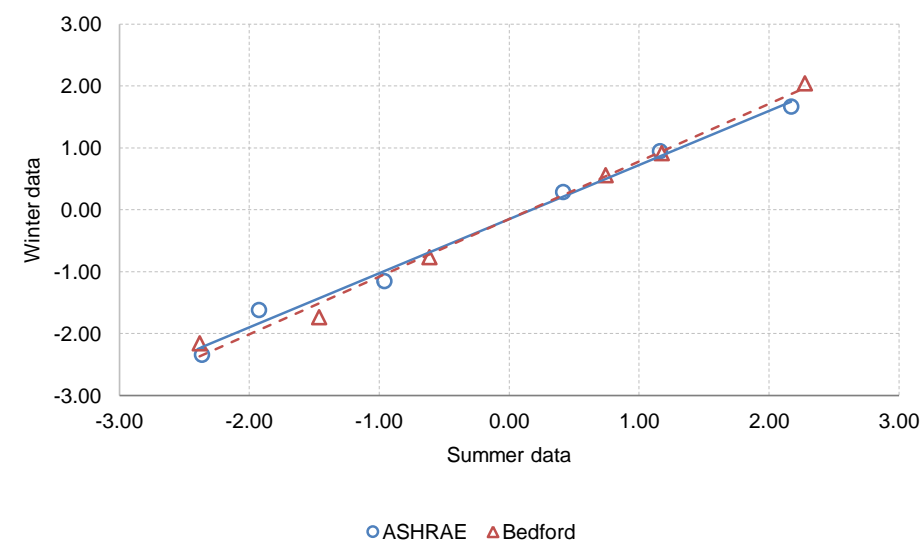

Figure 5: Comparing categories' widths of sensation scales

Besides, it is noted from Figure 5 that the plotted probits, that represent the categories upper limits, were on their assumed locations in both scales with few exceptions. In ASHRAE scale, both (cool) and (slightly cool) were shifted towards the cool side of the continuum. The exceptions in Bedford scale were (comfortable) and (comfortably warm) as the former category was shifted to the warm side as a result for the narrow width of the latter. 


\subsection{Centres of translated categories}

Based on the probits, the categories' centres were determined as presented in Table 4. It should be mentioned that the displayed centres are adjusted in order to maintain (0) as the centre of the middle categories. The computation of the centres is straightforward considering that the probits are the upper limits of the categories and it is possible to determine the centres of the end categories by two methods [18]. The first method was applied in Table 4. Considering the centres' adjustment, it is performed by moving the computed centres so the centre of the middle category coincides with the thermal continuum centre (i.e. zero point) while maintaining the standard deviation of the scale. First, the probit of the middle category is equalised to zero by subtracting or adding its absolute value. This step is then applied to the probits of the other categories. Second, the ratio between the standard deviations of the original scale (i.e. from -3 to +3 in the case of sensation scale for instance) and that resulted from the first step is determined. Third, the resulted values from the first step are multiplied by the ratio from the second step. As observed in Table 4, the actual categories' centres were different from those assumed, which confirms the change in the behaviour of the translated scales.

\begin{tabular}{|c|c|c|c|c|c|c|c|c|}
\hline \multirow{2}{*}{$\begin{array}{l}\text { Assumed } \\
\text { centres }\end{array}$} & \multicolumn{4}{|c|}{ Summer } & \multicolumn{4}{|c|}{ Winter } \\
\hline & ASHRAE & Nicol & Bedford & Nicol & Bedford & Nicol & ASHRAE & Nicol \\
\hline-3 & -2.34 & & -2.91 & & -2.66 & & -2.53 & \\
\hline-2 & -1.88 & - & -2.15 & -1.84 & -2.12 & -1.75 & -1.81 & -1.64 \\
\hline-1 & -1.17 & -0.79 & -1.19 & -1.05 & -1.32 & -1.04 & -1.12 & -0.97 \\
\hline 0 & 0.00 & 0.00 & 0.00 & 0.00 & 0.00 & 0.00 & 0.00 & 0.00 \\
\hline+1 & +1.06 & +1.06 & +0.97 & +1.03 & +0.96 & +1.06 & +1.23 & +1.06 \\
\hline+2 & +1.94 & +2.13 & +1.80 & +1.89 & +1.82 & +1.93 & +2.04 & +2.00 \\
\hline+3 & +2.71 & & +2.67 & & +2.78 & & +2.83 & \\
\hline
\end{tabular}

\section{Conclusion}

It is widely assumed that translating thermal scales maintain the characteristics of the original (English) scales. To investigate this assumption, the behaviour of Arabic translations of ASHRAE, Bedford, and Nicol scales was explored in this paper by applying the successive categories method. The translated scales were integrated into questionnaires that were distributed among female high school students in Muscat, Sultanate of Oman. The findings revealed that:

- The categories had irregular widths and the middle sensation categories were the widest indicating wide ranges of (neutral) and (comfortable) temperatures for the investigated students

- (Neutral) and (comfortable) categories covered different ranges on the thermal continuum despite their assumed equivalence with the former shifted to the cool side and the latter centred on the continuum centre 
- ASHRAE scale exhibited better symmetry around (neutral) category and Bedford scale exhibited a better seasonal response

- The shift of (neutral) and (no change) categories to the cool side of the thermal continuum may indicate the influence of the air conditioning systems on the investigated students

- Nicol scale had roughly equal width of categories and thus were relatively symmetrical around (no change) category

- The findings confirm that categories' widths are not affected by translation only.

- The computed centres of the scales' categories were different from those widely assumed

- The accuracy of the thermal comfort measurements applying regression analysis (like neutral temperature) is likely to be affected negatively.

Moreover, it was found that the deviations in the scales' behaviour were stable during the whole survey period. It should be mentioned that the calculated categories' widths should be considered as approximate estimations considering the relatively large standard errors of the categories' boundaries. Besides, the application of this investigation in female high schools is associated with some limitations. It was the first time for almost all the students to participate in a questionnaire and the majority thought that the questionnaires will be graded. This apparently may lead some of them to answer trying to please the researcher. Besides, some teachers were restricted regarding time, which created unnecessary tension on the students. Regarding the used phrases, the lack of differentiation between (cool) and (cold) in everyday Arabic vocabulary resulted in changing the covered range on the thermal continuum compared with the English version. It is recommended to conduct further explorations maintaining the implemented phrases of this study. This is because using other phrases may lead to other findings, which would be even interesting considering the lack of research regarding thermal scales' behaviour, especially in Arabic. Finally, it is worth mentioning that the successive categories method that was applied in this research has relatively a limited application in thermal comfort studies. However, it is useful in revealing the behaviour of thermal scales without the need to apply the free positioning task which is usually used to study the scales' behaviour. This has the advantage of reducing the questionnaires' size, which is usually reflected in an increased participation rate and, expectedly, increasing results' accuracy. 


\section{Acknowledgements}

The authors thank Sultan Qaboos University (SQU) for the generous financial funding of the PhD study of the first author. They also thank the Ministry of Education in the Sultanate of Oman for their support and the investigated schools for their participation.

Declaration of interest: None.

Funding: This research did not receive any specific grant from funding agencies in the public, commercial, or not-for-profit sectors.

\section{References}

[1] M.K. Nematchoua, R. Tchinda, J.A. Orosa, Thermal comfort and energy consumption in modern versus traditional buildings in Cameroon: A questionnaire-based statistical study, Appl. Energy. 114 (2014) 687-699. doi:10.1016/j.apenergy.2013.10.036.

[2] L. Yang, H. Yan, J.C. Lam, Thermal comfort and building energy consumption implications - A review, Appl. Energy. 115 (2014) 164-173. doi:10.1016/J.APENERGY.2013.10.062.

[3] H. Al-Khatri, M.B. Gadi, Using a New Programme to Predict Thermal Comfort as a Base to Design Energy Efficient Buildings, Int. J. Students' Res. Technol. Manag. 2 (2014) 172-177.

[4] M. Schweiker, X. Fuchs, S. Becker, M. Shukuya, M. Dovjak, M. Hawighorst, J. Kolarik, Challenging the assumptions for thermal sensation scales, Build. Res. Inf. 45 (2017) 572-589. doi:10.1080/09613218.2016.1183185.

[5] J.-Y. Lee, E.A. Stone, H. Wakabayashi, Y. Tochihara, Issues in combining the categorical and visual analog scale for the assessment of perceived thermal sensation: Methodological and conceptual considerations, Appl. Ergon. 41 (2010) 282-290. doi:10.1016/J.APERGO.2009.07.007.

[6] F. Nicol, M. Humphreys, S. Roaf, Adaptive thermal comfort: Principles and practice, 1st ed., Routledge, Oxon, 2012.

[7] M.A. Humphreys, M. Hancock, Do people like to feel 'neutral'?: Exploring the variation of the desired thermal sensation on the ASHRAE scale, Energy Build. 39 (2007) 867-874. doi:10.1016/J.ENBUILD.2007.02.014.

[8] A. Pitts, The language and semantics of thermal comfort, in: Wind. Conf. Comf. Energy Use Build., NCEUB (Network for Comfort and Energy Use in Buildings), Windsor, 2006: pp. 1-7.

[9] A.K. Mishra, M. Ramgopal, Field studies on human thermal comfort - An overview, Build. Environ. 64 (2013) 94-106. doi:10.1016/J.BUILDENV.2013.02.015.

[10] M.K. Singh, S. Mahapatra, S.K. Atreya, Adaptive thermal comfort model for different climatic zones of North-East India, Appl. Energy. 88 (2011) 2420-2428. doi:10.1016/J.APENERGY.2011.01.019.

[11] M.A. Humphreys, "Why did the piggy bark?" Some effects of language and context on the interpretation of words used in scales of warmth and thermal preference, in: Air Cond. Low Carbon Cool. Chall., NCEUB (Network for Comfort and Energy Use in Buildings), Windsor, 2008: pp. 1-14.

[12] R. de Dear, J. Kim, C. Candido, M. Deuble, Adaptive thermal comfort in Australian school classrooms, Build. Res. Inf. 43 (2015) 383-398. doi:10.1080/09613218.2015.991627.

[13] J. Wang, Z. Wang, R. de Dear, M. Luo, A. Ghahramani, B. Lin, The uncertainty of subjective thermal comfort measurement, Energy Build. 181 (2018) 38-49. doi:10.1016/J.ENBUILD.2018.09.041.

[14] H. Al-Khatri, M.B. Gadi, Collective understanding of ASHRAE thermal sensation phrases among Arab students, in: $L$. Brotas, S. Roaf, F. Nicol, M. Humphreys (Eds.), 10th Wind. Conf. - Rethink. Comf., NCEUB (Network for Comfort and Energy Use in Buildings), Windsor, 2018: pp. 357-370.

[15] N.H. Wong, S.S. Khoo, Thermal comfort in classrooms in the tropics, Energy Build. 35 (2003) 337-351. doi:10.1016/S0378-7788(02)00109-3.

[16] N.H. Wong, H. Feriadi, P.. Lim, K.. Tham, C. Sekhar, K.. Cheong, Thermal comfort evaluation of naturally ventilated public housing in Singapore, Build. Environ. 37 (2002) 1267-1277. doi:10.1016/S0360-1323(01)00103-2.

[17] H. Feriadi, N.H. Wong, Thermal comfort for naturally ventilated houses in Indonesia, Energy Build. 36 (2004) 614-626. doi:10.1016/J.ENBUILD.2004.01.011.

[18] M. Humphreys, F. Nicol, S. Roaf, Adaptive Thermal Comfort: Foundations and Analysis, 1st ed., Routledge, Oxon, 2016.

[19] B. Hamzah, Z. Gou, R. Mulyadi, S. Amin, B. Hamzah, Z. Gou, R. Mulyadi, S. Amin, Thermal Comfort Analyses of Secondary School Students in the Tropics, Buildings. 8 (2018) 1-19. doi:10.3390/buildings8040056.

[20] H.B. Rijal, T. Omori, M.A. Humphreys, F.J. Nicol, A field-comparison of thermal comfort with floor heating systems and air conditioning systems in Japanese homes, in: Wind. Conf. Count. Cost Comf. a Chang. World, NCEUB (Network for Comfort and Energy Use in Buildings), Windsor, 2014: pp. 1-9.

[21] A. Khatun, M.A. Hasib, H. Nagano, A. Taimura, Differences in reported linguistic thermal sensation between Bangla and Japanese speakers, J. Physiol. Anthropol. 36 (2017) 1-8. doi:10.1186/s40101-017-0139-5.

[22] X. Fuchs, S. Becker, K. Schakib-Ekbatan, M. Schweiker, Subgroups holding different conceptions of scales rate room temperatures differently, Build. Environ. 128 (2018) 236-247. doi:10.1016/J.BUILDENV.2017.11.034.

[23] K. Schakib-Ekbatan, S. Becker, A. Cannistraro, M. Schweiker, What do people associate with "cold" or "hot"? Qualitative analyses of the ASHRAE-scales' labels, in: L. Brotas, S. Roaf, F. Nicol, M. Humphreys (Eds.), 10th Wind. Conf. - Rethink. Comf., NCEUB (Network for Comfort and Energy Use in Buildings), 2018: pp. 371-385.

[24] S. Shahzad, J. Brennan, D. Theodossopoulos, J.K. Calautit, B.R. Hughes, Does a neutral thermal sensation determine thermal comfort?, Build. Serv. Eng. Res. Technol. 39 (2018) 183-195. doi:10.1177/0143624418754498.

[25] B. Koelblen, A. Psikuta, A. Bogdan, S. Annaheim, R.M. Rossi, Thermal sensation models: a systematic comparison, Indoor Air. 27 (2017) 680-689. doi:10.1111/ina.12329.

[26] F. Jazizadeh, F.M. Marin, B. Becerik-Gerber, A thermal preference scale for personalized comfort profile identification 
K. Parsons, Human Thermal Environments: The Effects of Hot, Moderate, and Cold Environments on Human Health, Comfort, and Performance, 3rd ed., CRC Press, Boca Raton, 2014.

[28] C. Holes, Modern Arabic: structures, functions, and varieties, 2nd ed., Georgetown University Press, Washington, D.C., 2004.

[29] I. Nam, J. Yang, D. Lee, E. Park, J.-R. Sohn, A study on the thermal comfort and clothing insulation characteristics of preschool children in Korea, Build. Environ. 92 (2015) 724-733. doi:10.1016/J.BUILDENV.2015.05.041.

[30] M.C. Katafygiotou, D.K. Serghides, Indoor comfort and energy performance of buildings in relation to occupants' satisfaction: investigation in secondary schools of Cyprus, Adv. Build. Energy Res. 8 (2014) 216-240. doi:10.1080/17512549.2013.865554.

[31] H. Yan, L. Yang, Indoor thermal conditinos and thermal comfort in residential buildings during the winter in Lhasa, China, in: Wind. Conf. Count. Cost Comf. a Chang. World, NCEUB (Network for Comfort and Energy Use in Buildings), Windsor, 2014: pp. 1-19.

[32] J. Kim, R. de Dear, C. Cândido, H. Zhang, E. Arens, Gender differences in office occupant perception of indoor environmental quality (IEQ), Build. Environ. 70 (2013) 245-256. doi:10.1016/J.BUILDENV.2013.08.022.

[33] L. Schellen, M. Loomans, M. de Wit, W. van Marken Lichtenbelt, The influence of different cooling techniques and gender on thermal perception, Build. Res. Inf. 41 (2013) 330-341. doi:10.1080/09613218.2013.772002.

[34] S. Karjalainen, Thermal comfort and gender: a literature review, Indoor Air. 22 (2012) 96-109. doi:10.1111/j.16000668.2011.00747.x.

[35] S. Karjalainen, Gender differences in thermal comfort and use of thermostats in everyday thermal environments, Build Environ. 42 (2007) 1594-1603. doi:10.1016/J.BUILDENV.2006.01.009.

[36] Z. Wang, A field study of the thermal comfort in residential buildings in Harbin, Build. Environ. 41 (2006) 1034-1039. doi:10.1016/J.BUILDENV.2005.04.020.

[37] K.C. Parsons, The effects of gender, acclimation state, the opportunity to adjust clothing and physical disability on requirements for thermal comfort, Energy Build. 34 (2002) 593-599. doi:10.1016/S0378-7788(02)00009-9.

[38] N.A. Al-Azri, Y.H. Zurigat, N.Z. Al-Rawahi, Development of bioclimatic chart for passive building design, Int. J. Sustain Energy. 32 (2013) 713-723. doi:10.1080/14786451.2013.813026.

[39] F. Ragette, Traditional Domestic Architecture of the Arab Region, 1st ed., American Univeristy of Sharjah, Zlin, 2012.

[40] A. Konya, M. Vandenberg, Design primer for hot climates, Archimedia Press Limited, Reading, 2011.

[41] H. Al-Gharibi, Urbanisation and changing lifestyle patterns in Muscat, in: S. Nebel, A. von Richthofen (Eds.), Urban Oman Trends Perspect. Urban. Muscat Cap. Area, LIT Verlag, Zurich, 2016: pp. 73-79.

[42] N.H.A. Majid, N. Takagi, S. Hokoi, S.N.N. Ekasiwi, T. Uno, Field survey of air conditioner temperature settings in a hot, dry climate (Oman), HVAC\&R Res. 20 (2014) 751-759. doi:10.1080/10789669.2014.953845. 


\title{
Investigating the behaviour of ASHRAE, Bedford, and Nicol thermal scales when translated into the Arabic language
}

\author{
Hanan Al-Khatri ${ }^{1,2, *}$ and Mohamed B. Gadi ${ }^{1}$ \\ ${ }^{1}$ Department of Architecture and Built Environment, Faculty of Engineering, University of Nottingham, Nottingham, NG7 2RD, \\ United Kingdom, E-mail: Hanan.Al-Khatri@nottingham.ac.uk (Hanan Al-Khatri), mohamed.gadi@nottingham.ac.uk (Mohamed \\ B. Gadi) \\ ${ }^{2}$ Department of Civil and Architectural Engineering, College of Engineering, Sultan Qaboos University, P.O. Box 33, Al-Khod, \\ Muscat, 123, Sultanate of Oman, E-mail: khatri@squ.edu.om \\ "Corresponding author, E-mail address: hanan.khatr@@gmail.com, Tel: +44(0)1159515559, Fax: + 44(0)1159514115
}

\begin{abstract}
With the global spread of thermal comfort studies, thermal scales are translated into different languages to adapt local context in which the studies are applied. However, translating thermal comfort studies does not maintain the scales' behaviour associated with the original English versions. Behaviour differences include irregular categories' width, asymmetry, and deviation of the middle category centre from the centre of the thermal continuum. These differences have a negative influence on the results of thermal comfort studies and their accuracy. Applying the successive categories method, this paper explores the change in ASHRAE, Bedford, and Nicol scales' behaviour when translated into the Arabic language. The translated scales were integrated into questionnaires distributed among female high school students in Muscat, the capital city of Oman, as part of a larger survey that lasted for a whole year. The findings revealed the deviation of the translated scales from the original assumptions of the English versions. This included categories' irregular widths and asymmetry in addition to the deviation of the centre of the middle categories from the centre of the thermal continuum. Besides, it was found that both ASHRAE and Bedford scales covered different ranges on the thermal continuum, which questions their assumed equivalence. Based on these findings, the accuracy of the thermal comfort analysis is negatively affected. Considering the sensitivity of scales' behaviour to the used phrases, further explorations implementing the terms examined in this study are recommended.
\end{abstract}

Keywords: Thermal scale; thermal comfort; translation influence; Successive categories method; Arabic language; Oman

\section{Introduction}

Satisfying thermal comfort requirements of buildings' occupants is a considerable challenge for two reasons. First, these requirements are generally an important consumer of energy in buildings $[1,2]$. Second, thermal comfort has a subjective nature that requires a good understanding of users' thermal demands [3]. With the aim of contributing towards this understanding, researchers usually conduct thermal comfort studies inside real buildings. In these studies, they often distribute questionnaires that involve using thermal scales as a major tool to seek participants' thermal sensations. Voting a thermal sensation requires the subjects to feel, evaluate, and express their thermal states using thermal scales. It is possible to consider these word-based scales as numerical measures of subjective 
experience as the thermal votes obtained from the distributed questionnaires are usually expressed in numerical form for analysis purposes.

Among several sensation scales found in the literature [4,5], ASHRAE and Bedford scales are widely used. Both scales consist of seven categories that are usually converted during analysis into a numerical range from $(-3)$ to $(+3)$ as follows:

- ASHRAE scale: cold (-3), cool (-2), slightly cool $(-1)$, neutral (0), slightly warm $(+1)$, warm (+2), hot $(+3)$

- Bedford scale: much too cool (-3), too cool (-2), comfortably cool (-1), comfortable neither warm nor cool $(0)$, comfortably warm $(+1)$, too warm $(+2)$, much too warm $(+3)$

Moreover, thermal preference scales are mainly introduced to overcome possible confusion between neutrality and culturally desirable sensations [6-8]. McIntyre, Nicol, and a modified version of ASHRAE sensation scales are widely used to report thermal preferences. These scales have three, five, and seven categories respectively as follows:

- McIntyre scale: warmer (-1), no change (0), cooler $(+1)$

- Nicol scale: much warmer (-2), a bit warmer (-1), no change (0), a bit cooler (+1), much cooler

- ASHRAE scale: much warmer (-3), warmer (-2), slightly warmer (-1), no change (0), slightly cooler $(+1)$, cooler $(+2)$, much cooler $(+3)$

\subsection{Challenges in using thermal sensation scales}

Despite the continuous implementation of thermal sensation scales, there are some challenges in applying them. These challenges may be classified into those related to scales in their English or original form and those related to the translated versions. The reasons for these challenges include the difference between neutrality and comfort, the effect of the climatic and cultural background, and participants' difference in realising thermal sensations and their distribution on the thermal continuum [8]. Additional reasons include the variations that result from translation. Translating thermal scales has a positive impact on the participation rate as it adapts the scales to the local context $[9,10]$. However, deviations from the original English scales exist due to the absence of equivalent sensations in the translated languages or the difference in the impressions associated with these sensations [11].

Examples of such challenges include the statistical evidence on the different interpretations of ASHRAE sensation scale [7]. Another is the use of a numerical system to describe a psychological 
experience [6]. Some studies attempt to overcome this via using continuous scales like the study of [12]. According to McIntyre cited in [4], employing continuous scales may reflect accurate sensations, especially under slight or slow variations of temperature. However, such scales may be impractical, introduce errors [6], and reduce the results' accuracy [13].

Regardless of the widely accepted assumption of exchangeable use of ASHRAE and Bedford scales, the former assumes that thermal comfort is equivalent to any sensation from the central categories (i.e. slightly cool, neutral, slightly warm), whereas the latter integrates (comfort) in its categories. The inequality between neutrality and comfort was proven statistically in a study that requested the subjects to identify thermal comfort along ASHRAE scale. The findings indicated that neutrality was cooler than comfort for the involved participants. It is worth mentioning that this study was conducted in winter with a majority of English participants [8]. A similar result was found in a recent study conducted for a whole year among Eastern Arabs; yet, neutrality was warmer than comfort, which can be justified by the influence of the climatic background of the participants [14].

Furthermore, some studies highlighted few discrepancies in the exchangeable use of ASHRAE and Bedford scales $[9,15,16]$. For instance, accepting thermal surroundings was higher by about $20 \%$ using Bedford scale compared with ASHRAE in a study that took place in a high school in Singapore. In this study, thermal acceptability and the votes in the central categories were assumed to be equivalent [15]. However, scales' difference may be due to their use in that study as ASHRAE scale was applied to evaluate ambience temperature and Bedford scale was applied to evaluate thermal sensation.

In another study that compared Indonesian translations of both scales, variations in votes' distribution were revealed. In specific, ASHRAE votes distributed relatively evenly, whereas Bedford votes clustered in central categories. Accordingly, the researchers concluded that ASHRAE scale had a better behaviour [17], which may justify their use of ASHRAE data in their analysis. However, applying successive categories method indicated that Bedford scale behaved better [18] and, thus, computing neutral temperature using its data may lead to conclusions with better accuracy. Additionally, a similar clustering of thermal votes using Bedford scale in the central categories compared with ASHRAE scale was reported in [19]. The clustering behaviour of Bedford votes may indicate a lack of sensitivity [5] and the reasons for this pattern of distribution are not clearly known. It is probably due to people variation in their perception to thermal ambience or their interpretation of thermal scales [4]. 
Another possible reason is the integration of (comfort) in the central categories; usually, people tend to keep themselves thermally comfortable as indicated by the adaptive principle.

Considering the challenges associated with translation, the translated thermal scales deviates from the assumptions of the English scales and, consequently, changes their behaviour. Examples of these deviations include the divergence of the middle category centre from (zero), unequal width of categories, and asymmetrical categories. Such changes were reported when translating ASHRAE and Nicol scales into French, Swedish, Portuguese, and Greek languages [11,18]. Similar changes in scales' behaviour were revealed in a study that translated both scales into Japanese and compared their behaviour with a Japanese scale $[18,20]$. Likewise, comparing the translated sensation phrases used in some Arabic studies of thermal comfort revealed that the translated phrases associated possibly desirable impressions to sensations outside the three central categories. Besides, the translated scales covered different ranges on the thermal continuum compared with the ASHRAE or Bedford 7-points scales [14].

It should be mentioned that these variations in scales' behaviour are not attributed to the translation effect solely. Climatic background and acclimatisation can be considered as other contributors [18]. In this regard, a recent study investigated the climatic effect on thermal responses and terms of Bangladeshi and Japanese participants. A translated version of ASHRAE 11-point scale was integrated in the distributed questionnaire besides imaginary thermal scenarios at which participants should describe their sensations. Significant variations in thermal sensations were reported, which emphasises the impact of the climatic background [21].

\subsection{Thermal scales in literature}

This section presents the literature concerned with thermal scales to highlight the lack of research regarding the behaviour of translated thermal scales applying the successive categories method, which is the focus of this paper. Indeed, there are few studies concerned with thermal scales in general [22] despite their wide applications in thermal comfort studies. Reviewing the literature revealed recent investigations regarding different aspects of thermal scales including people interpretation of thermal scales $[8,11,14,22,23]$, examining the scales' assumptions $[4,8,14]$, the relationship between comfort and neutrality $[8,11,14,24]$, uncertainty of thermal comfort measurements related to thermal scales and survey protocol [13], comparing different thermal scales $[5,25]$, and proposing a new preference scale [26]. As noted, the majority of these studies were published during the last year. 
People vary in their interpretation of thermal scales, which was noted in studies like $[4,8,14]$. These variations include the differentiation between phrases, identification of the phrases' positions and distances, and the concepts associated with each sensation. For instance, a relatively weak differentiation between (slightly cool) and (cool) as well as between (slightly warm) and (warm) were revealed among Eastern Arab students. Linking this to the participants' climatic background highlights the importance of considering it when translating thermal scales and defining thermal comfort zone [14]. People's variations in identifying the positions of and the distances between ASHRAE sensation phrases were not random from a statistical point of view. This implies that comfort is not necessarily related to the three central thermal sensations as widely assumed. Interestingly, grouping participants based on these variations can increase the prediction accuracy of thermal comfort models [22]. In this regard, the generalisation of thermal votes was questioned based on the different conceptions and experiences associated with the sensation phrases of ASHRAE scale [23].

Regarding the scales' assumptions, it was revealed that the assumptions of equal categories' width and comfort range may not be valid and the used scale type (ordinal or continuous) affects survey results. This implies that temperature steps, which are the temperature changes required to move by one thermal sensation, are not necessarily uniform [4]. However, these findings may require further examination considering the sample size of the experiment.

Moreover, the degree of which thermal neutrality can be considered as an indication of thermal comfort was investigated by a recent study conducted in Norwegian and British offices. The study highlighted that ASHRAE definition of thermal comfort does not refer to neutrality; yet, several studies of thermal comfort considered them as equivalents. The findings confirm the difference between comfort and neutrality as around $36 \%$ and $60 \%$ of the participants in the questionnaires and interviews respectively wanted different sensations than neutrality [24], which was highlighted in other studies $[8,11,14]$.

Additionally, the effect of the survey protocol, including participants' number and votes per participant number, and questionnaire characteristics, including scale type (continuous or discrete) and choices' number, on the intra-individual and subjective measurement uncertainty was investigated. The intraindividual variation refers to the change in the one participant votes under similar thermal environments. It is recommended to use discrete thermal scales of no more than 7-points to reduce 
the intra-individual variations. Increasing the number of votes per person has a positive influence on the subjective measurement uncertainty and a recommended number is 40 person-votes [13]. Some researchers investigated the assumption of equivalence between the different thermal scales $[5,25]$. The former study highlighted the absence of a well-established base to compare thermal sensation scales. The researchers suggested considering the scales with an equal number of categories equivalent although they differ in the associated phrases. Besides, they suggested unifying the length of scales with different categories number by categories' redistribution [25]. Obviously, this attempt involves changing the original widths of categories besides assuming equality between extreme sensations. It is worth to mention that such equality lacks evidence. Moreover, exploring scales' behaviour, by applying the successive categories method, may reveal some variations in the scales' behaviour despite their equal number of categories. In another study, the application of a categorical scale, a visual analogue scale, and a combined scale with visual analogue and categorical features was explored by integrating them in a questionnaire besides an accompanied experiment. The scales were translated into Korean and Japanese to suit participants' mother tongue. It was found that verbal scales expressed thermal sensations more precisely and exhibited higher correlations with indoor air temperature compared with visual scales [5].

Furthermore, an application was designed to collect users' thermal preference votes promptly using their smartphones or computers. The integrated scale implemented ASHRAE phrases except (slightly cool) and (slightly warm). The results indicated the application success in fulfilling its purpose.

Besides, the accompanied field study revealed that preference votes were mostly influenced by the ambient temperature [26]. It is noteworthy that exploring the properties of the used scale was out of scope in that study.

\subsection{Research aim}

Translated thermal scales are supposed to maintain the assumptions of their English versions (original version). However, maintaining a similar behaviour is affected by the characteristics of the translated language and the accuracy of the translation. Any deviation from the scales' original assumptions has a negative influence on the results of the thermal comfort studies. For instance, the irregularity in categories' widths had a negative effect on the results of the regression analysis. This analysis is widely applied in the thermal comfort studies and it requires equal intervals of both the dependent and independent variables [6]. The paper at hand attempts to explore the behaviour of ASHRAE, Bedford, and Nicol scales when translated into the Arabic language applying the 
successive categories method; in particular, it investigates to which extent do the translated scales maintain equal distances between categories, symmetry around the middle category, and the coincidence between the middle category and the centre of the thermal continuum. These assumptions were investigated in previous studies using free positioning only where the participants were requested to distribute thermal phrases on the thermal continuum $[4,8,14]$. Up to the knowledge level of the authors, this study is the first concerning thermal scales translated into the Arabic language.

In this research, the investigated phrases covered a range on the continuum similar to that covered by the internationally agreed Arabic version, which is available in [27]. However, the phrases of this version were not applied in the current research because they are not commonly used in the Eastern Arabic region that includes Oman, where the investigation was applied. It is worth to mention that the Arabic language has different dialects and the used vocabulary is affected by the geographical origin of the speaker [28].

As noted from sections (1.1.) and (1.2.), there is a lack of research regarding the behaviour of translated thermal scales, especially when translated into the Arabic language, despite the recent interest in studying thermal scales. Additionally, few thermal comfort studies are generally conducted in the Arabic region regardless of its extreme climatic conditions and the high dependence on nonrenewable energy in satisfying thermal comfort demands. It is hoped that this study will contribute towards filling this gap of knowledge and encourage other researchers to carry out more thermal comfort research in the Arabic region as well as to apply the successive categories method to investigate the thermal scales' behaviour.

\section{Methodology}

The investigated scales in this study (i.e. ASHRAE, Bedford, and Nicol) were integrated into two questionnaires distributed among high school students as part of a thermal survey that was conducted for a whole academic year. The successive categories method was applied to compare the scales' behaviour and examine their stability during the survey. Widely used in psychometric studies, the method is recently implemented to explore the properties of the thermal scales by defining the actual width of the scales' categories as perceived by the participants. This enables comparing the categories' widths and their relative positions and, thus, exploring the scales' behaviour. To apply the method, the compared scales should be derived from the same survey, i.e. the same subjects and 
similar thermal conditions. Although the method may not be accurate for extreme categories (i.e. cold and hot in ASHRAE sensation scale for instance), the formed conclusions are generally not influenced as usually very few votes fall in those categories [18].

In general, comparing the behaviour of thermal scales includes making assumptions regarding the participants' response or regarding the thermal conditions. For instance, some studies assumed that different participants, answering questionnaires with different scales, have almost similar responses under identical conditions like [5]. Other attempts like [15] involved distributing a questionnaire with more than one thermal sensation scale to the same participants. Neither approach is theoretically correct because of the participants' change in the former study and the time lag in the latter.

Moreover, distributing more than one sensation scale within the same questionnaire increases the risk of subjects' boredom due to questions' repetition. In the research reported in this paper, the same participants answered questionnaires that integrated the explored scales separated by time lag under similar thermal conditions.

\subsection{Data}

The data analysed in this paper are part of a thermal survey conducted in Muscat, the capital city of the Sultanate of Oman. Five female high schools were visited twice in summer and three of them were visited twice in winter. Two schools were excluded from winter study because of unforeseen problems. In total, 15 and 9 classrooms were visited in summer and winter respectively. In each visit, the classrooms' objective data represented in the indoor air temperature, globe temperature, relative humidity, and air velocity were collected for a whole school day. Besides, a questionnaire was distributed among the students once towards the end of the fourth, fifth, or sixth class. The questionnaire integrated a translated version of ASHRAE or Bedford sensation scale, whereas Nicol preference scale was integrated into all questionnaires' versions. The sequence of distributing the questionnaires is illustrated in Figure 1. Besides, the translated head questions and the translated phrases of scales' categories are displayed in Table 1. These translations are included because the scales' behaviour depends on the used terms, i.e. it is possible for two scales translated into one language using different terms to behave differently [18]. 


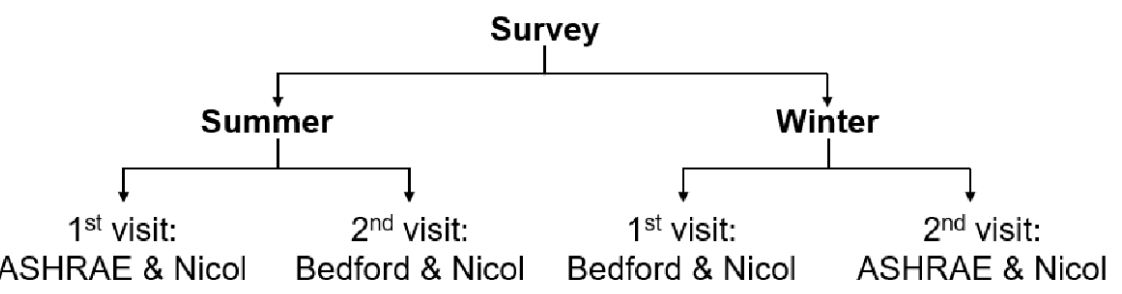

Figure 1: Sequence of questionnaires' distribution

\begin{tabular}{|c|c|c|c|c|c|}
\hline \multicolumn{2}{|c|}{ ASHRAE } & \multicolumn{2}{|c|}{ Bedford } & \multicolumn{2}{|c|}{ Nicol } \\
\hline English & Arabic & English & Arabic & English & Arabic \\
\hline Currently, I feel: & حاليا، أشعر بـ: & Currently, I feel: & حاليا، أشعر ب-: & $\begin{array}{l}\text { Currently, I would } \\
\text { prefer to be: }\end{array}$ & حاليا، أريد أن أكون: \\
\hline Cold & باردة جدا & Much too cool & باردة جدا & Much warmer & أسخن كثير ا \\
\hline Cool & باردة & Too cool & باردة & A bit warmer & أسخن قليلا \\
\hline Slightly cool & باردة قليلا & Comfortably cool & باردة لكن مرتاحة & No change & لا تغيير \\
\hline Neutral & معتدلة & $\begin{array}{l}\text { Comfortable, neither } \\
\text { cool nor warm }\end{array}$ & مرتاحة لا باردة و لا & A bit cooler & أبرد قليلا \\
\hline Slightly warm & ساخنة قليلا & Comfortably warm & ساخنة لكن مرتاحة & Much cooler & أبرد كثير ا \\
\hline Warm & ساخنة & Too warm & ساخنة & & \\
\hline Hot & ساخنة جدا & Much too warm & ساخنة جدا & & \\
\hline
\end{tabular}

As noted from Table 1, the non-central categories of ASHRAE and Bedford scales (i.e. categories -3, $-2,+2$, and +3 ) were translated to identical Arabic phrases. This allows exploring the stability of these categories' behaviour besides exploring the translation impact on comfort range (i.e. the three central categories). It is noteworthy that both (cool) and (cold) words are often translated into one term in the Arabic language. To distinguish between the two sensations, the latter was literally translated as (very cold). Moreover, the literal translation of (warm) may be a desirable sensation especially in winter; thus, it was translated to a phrase that means (hot) to convey the negative impression of this category. This led to translating (hot) as (very hot), which additionally maintained the scales' symmetry. Consequently, the thermal ranges covered by the two scales' versions (i.e. English and Arabic) are different; yet, this change is acceptable as it is part of adapting scales to the local context. In the Smart Controls and Thermal Comfort (SCAT) project, the French, Greek, and Portuguese versions of the scale were manipulated in a similar manner [11]. Despite this difference in the thermal ranges, both English and Arabic scales' versions are assumed to maintain similar uniform gaps between the consecutive sensations.

\subsection{Participants}

The research presented in this paper is a part of a larger survey that requires participants with a certain level of English language capacity. The participated students spent at least nine years studying English as a second language and, thus, had acquired a suitable level of the language for the survey. However, the genders separation of the Omani educational system, the conservative 
nature of the Omani society, and the lack of resources to recruit male research assistants to distribute the questionnaires among male participants can create a selection bias. Consequently, votes' clustering in some categories may occur as noted in previous studies [29-37] that explored the difference in thermal responses among different genders. This votes' clustering may have an influence on the categories' boundaries. However, the nature of the exploration reported in this paper does not 'really' require a representative sample as stated by [7]: "For an exploration of the interior dynamic of the scale, it was not necessary to choose respondents by representative sampling, nor thermal environments strictly representative of the respondents' thermal experience, and nor was comprehensive measurement of the thermal environment required."

\subsection{Site description and selected schools} Located at $23.61^{\circ} \mathrm{N}$ longitude and $58.54^{\circ} \mathrm{E}$ latitude, Muscat is the capital city of Sultanate of Oman. According to Koppen-Geiger climate classification, the city is located within a desert hot arid region. However, its mountainous nature and proximity from the Indian Ocean changed that climate to a hot and humid one [38-40]. It is possible to distinguish two climatically distinctive periods in the city. The first starts in April and extends to October and it forms the hot humid period. Maximum air temperature reaches $45^{\circ} \mathrm{C}$ in May and the mean extends from $30^{\circ} \mathrm{C}$ in April and October to $35^{\circ} \mathrm{C}$ in June. Mean relative humidity extends between $42 \%$ and $74 \%$ in May and August respectively. The other period is relatively cooler as mean air temperature extends between $21^{\circ} \mathrm{C}$ in January and $26{ }^{\circ} \mathrm{C}$ in November and mean relative humidity ranges from $57 \%$ to $66 \%$ in March and December respectively. It is noteworthy that temperature drop at night is minor in Muscat because the basaltic rock formations in the city release the heat absorbed during daytime causing continuous high temperatures and relative humidity [39].

There are 10 governmental high schools for female students in Muscat city. Two of these schools are located in rural areas, which make their participation in the research inconvenient. Thus, a primary list of the schools consisted of a convenient sample that included eight governmental schools. They were classified into four groups based on their architectural style, namely courtyards, clustered courtyards, linear form, and a combination of courtyards and wings. One school from each group was selected to participate in the survey. A fifth school was investigated because it has three floors, unlike the other schools that have two floors only. It is worth mentioning that private schools were excluded from this investigation due to the limited number of students in each classroom. 


\section{Results and discussion}

Recalling that applying successive categories method requires deriving the explored scales from one thermal survey, the thermal environments of the participated classrooms were investigated to ensure that the students were subjected to similar conditions. It was found that some classrooms were thermally different. Therefore, all questionnaires from these classrooms were excluded from the analysis below. Discussing the thermal conditions of the investigated classrooms is out of this paper's scope. Besides, the questionnaires returned from students who were involved in physical education classes before participating in the survey were excluded. As a result, 333 and 349 copies of ASHRAE and Bedford questionnaires respectively of summer study were included in the analysis. The corresponding copies of winter study were 209 and 194.

The successive categories method was applied to determine the probits that represent the categories upper limits. To compute the probits, the students' votes in each category were determined and the cumulative numbers of votes were calculated. The cumulative proportion of each category was computed by dividing the cumulative number of votes in that category by the total number of votes. The cumulative proportions were then transformed into probits using the cumulative normal distribution of unit standard deviation on the psychological continuum. The application of the successive categories method in the thermal comfort field is comprehensively illustrated in chapter (18) of Adaptive Thermal Comfort: Foundations and Analysis book [18].

The computed probits of thermal scales in summer are displayed in Table 2 and those in winter are presented in Table 3. To visualise the findings, graphical representations of the tables are demonstrated in Figure 2 for the former and in Figure 3 for the latter. Based on these tables and figures, it is possible to compare the translated scales and investigate their behaviour through comparison with the original assumptions of the English scales. In particular, the categories' width and symmetry can be obtained from these figures besides the coincidence between the scales' middle categories and the thermal continuum centre. More details are discussed in the following sections. 


\begin{tabular}{|c|c|c|c|c|c|c|}
\hline \multirow[b]{2}{*}{ Category } & \multicolumn{3}{|c|}{ ASHRAE, N = 333} & \multicolumn{3}{|c|}{ Bedford, N = 349} \\
\hline & Cum. Prop. & Probit & SE & Cum. Prop. & Probit & SE \\
\hline-3 & 0.009 & -2.37 & 0.173 & 0.009 & -2.38 & 0.172 \\
\hline-2 & 0.027 & -1.93 & 0.126 & 0.072 & -1.46 & 0.094 \\
\hline-1 & 0.168 & -0.96 & 0.079 & 0.269 & -0.61 & 0.070 \\
\hline 0 & 0.661 & 0.41 & 0.072 & 0.771 & 0.74 & 0.076 \\
\hline+1 & 0.877 & 1.16 & 0.093 & 0.880 & 1.17 & 0.092 \\
\hline+2 & 0.985 & 2.17 & 0.224 & 0.989 & 2.27 & 0.252 \\
\hline \multirow[t]{2}{*}{+3} & 1.000 & - & - & 1.000 & - & - \\
\hline & \multicolumn{3}{|c|}{ Nicol (ASHRAE), N = 333} & \multicolumn{3}{|c|}{ Nicol (Bedford), N = 349} \\
\hline-2 & 0.000 & - & - & 0.006 & -2.53 & 0.193 \\
\hline-1 & 0.111 & -1.22 & 0.086 & 0.135 & -1.10 & 0.081 \\
\hline 0 & 0.351 & -0.38 & 0.070 & 0.507 & 0.02 & 0.067 \\
\hline+1 & 0.814 & 0.89 & 0.083 & 0.917 & 1.38 & 0.104 \\
\hline+2 & 1.000 & - & - & 1.000 & - & - \\
\hline \multicolumn{7}{|c|}{ Table 2: Cumulative proportions, probits, and standard errors of thermal categories (summer) } \\
\hline & \multicolumn{3}{|c|}{ Bedford, $\mathbf{N}=194$} & \multicolumn{3}{|c|}{ ASHRAE, N = 209} \\
\hline Category & Cum. Prop. & Probit & SE & Cum. Prop. & Probit & SE \\
\hline-3 & 0.015 & -2.16 & 0.186 & 0.010 & -2.34 & 0.206 \\
\hline-2 & 0.041 & -1.74 & 0.143 & 0.053 & -1.62 & 0.130 \\
\hline-1 & 0.222 & -0.77 & 0.097 & 0.124 & -1.15 & 0.105 \\
\hline 0 & 0.711 & 0.56 & 0.098 & 0.612 & 0.29 & 0.089 \\
\hline+1 & 0.820 & 0.91 & 0.111 & 0.828 & 0.95 & 0.108 \\
\hline+2 & 0.979 & 2.04 & 0.270 & 0.952 & 1.67 & 0.171 \\
\hline \multirow[t]{2}{*}{+3} & 1.000 & - & - & 1.000 & - & - \\
\hline & \multicolumn{3}{|c|}{ Nicol (Bedford), N = 194} & \multicolumn{3}{|c|}{ Nicol (ASHRAE), N = 209} \\
\hline-2 & 0.005 & -2.57 & 0.250 & 0.005 & -2.59 & 0.248 \\
\hline-1 & 0.088 & -1.36 & 0.118 & 0.062 & -1.54 & 0.124 \\
\hline 0 & 0.448 & -0.13 & 0.090 & 0.344 & -0.40 & 0.088 \\
\hline+1 & 0.871 & 1.13 & 0.123 & 0.804 & 0.86 & 0.104 \\
\hline+2 & 1.000 & - & - & 1.000 & - & - \\
\hline
\end{tabular}

Table 3: Cumulative proportions, probits, and standard errors of thermal categories (winter)

Nicol (Bedford)

Nicol (ASHRAE)

Bedford

ASHRAE

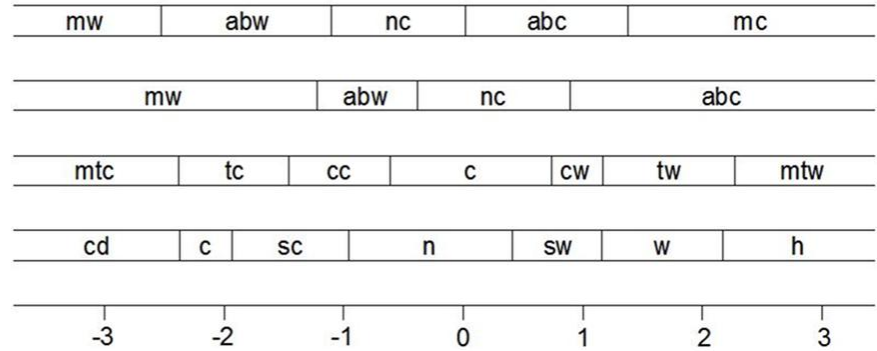

Key:

ASHRAE: $\mathrm{cd}=\mathrm{Cold}, \mathrm{cl}=\mathrm{Cool}, \mathrm{sc}=$ Slightly cool, $\mathrm{n}=$ Neutral, $\mathrm{sw}=$ Slightly warm, $\mathrm{w}=\mathrm{Warm}, \mathrm{h}=\mathrm{Hot}$

Bedford: $\mathrm{mtc}=$ Much too cool, tc $=$ Too cool, $\mathrm{cc}=$ Comfortably cool, $\mathrm{c}=$ Comfortable neither warm nor cool,

$\mathrm{cW}=$ Comfortably warm, $\mathrm{tw}=$ Too warm, $\mathrm{mtw}=$ Much too warm

Nicol: $\mathrm{mw}=$ Much warmer, $\mathrm{abw}=\mathrm{A}$ bit wamer, $\mathrm{nc}=$ no change, $\mathrm{abc}=\mathrm{A}$ bit cooler, $\mathrm{mc}=$ Much cooler

Figure 2: Comparing thermal categories' widths of ASHRAE, Bedford, and Nicol scales in summer

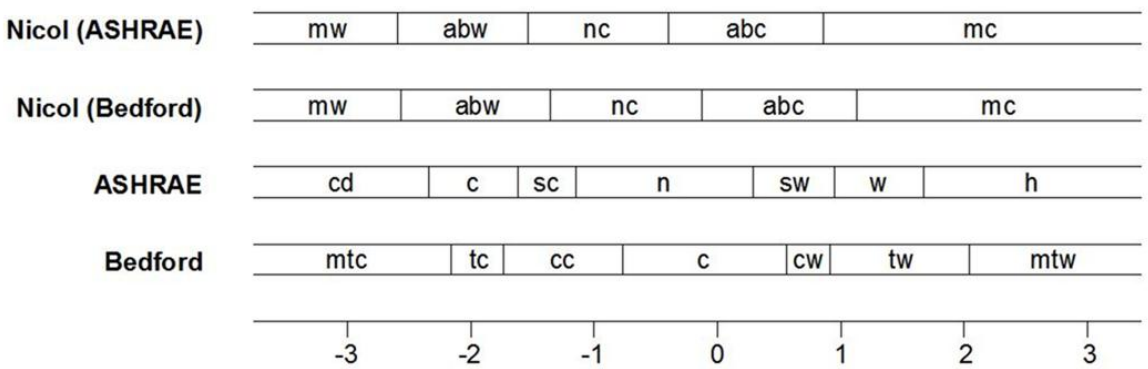

Key:

ASHRAE: $c d=$ Cold,$c l=$ Cool,$s c=$ Slightly cool $n=$ Neutral, $s w=$ Slightly warm, $w=$ Warm, $h=$ Hot

Bedford: $\mathrm{mtc}=$ Much too cool, $\mathrm{tc}=\mathrm{Too} \mathrm{cool}, \mathrm{cc}=$ Comfortably cool, $\mathrm{c}=$ Comfortable neither warm nor cool,

$\mathrm{cw}=$ Comfortably warm, $\mathrm{tw}=$ Too warm, $\mathrm{mtw}=$ Much too warm

Nicol: $\mathrm{mw}=$ Much wamer, $\mathrm{abw}=\mathrm{A}$ bit warmer, $\mathrm{nc}=$ no change, $\mathrm{abc}=\mathrm{A}$ bit cooler, $\mathrm{mc}=$ Much cooler

Figure 3: Comparing thermal categories' widths of Bedford, ASHRAE, and Nicol scales in winter 


\subsection{Categories' widths}

In the following sections, the categories' widths are compared at three levels as illustrated in Figure 4. In the first level, the categories' widths are compared within each scale. In the second, the compared categories are from different scales. This includes comparing widths of ASHRAE and Bedford categories besides comparing them with those of Nicol scale. Considering the third level, it compares the widths of the same categories from different questionnaires within the same survey.

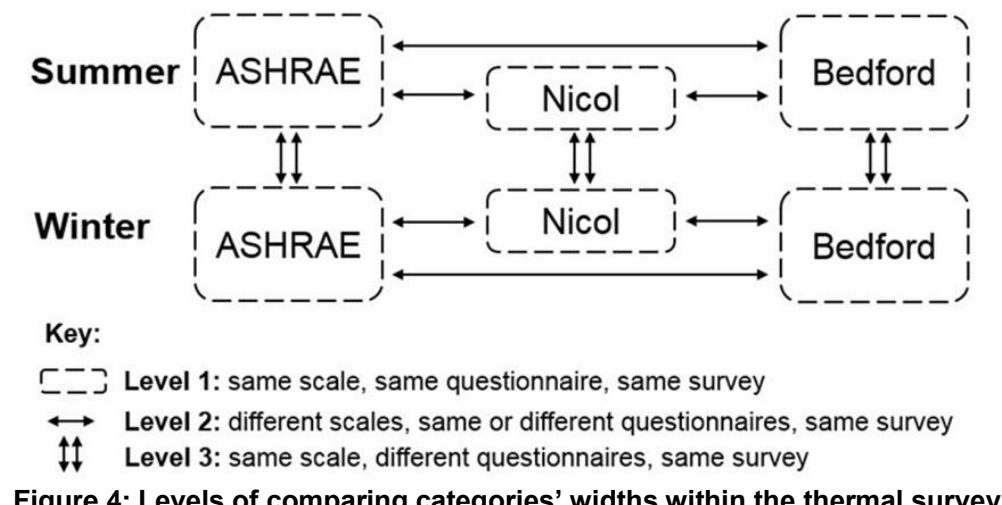

\subsubsection{Comparing categories' widths within each scale}

As noted in Figure 2 and Figure 3, the widths of sensation categories were irregular in both seasons.

Accordingly, moving between categories required unequal temperature steps besides applying regression analysis, to compute the neutral temperature for instance, may not be totally accurate as the equation is negatively influenced by these irregularities. The middle categories are the widest, which indicates that wide ranges of temperature are considered (neutral) or (comfortable) for the investigated students. In both seasons, (comfortably warm) category was noticeably narrow perhaps for climatic and cultural reasons as it is possible that the students found it difficult to combine comfort with a warm sensation. Regarding Nicol scale, roughly uniform temperature differences were required to move between preference categories due to their relatively equal widths. It is noteworthy that (a bit cooler) category during ASHRAE questionnaire of summer study had no defined width owing to votes' absence in (much cooler) category. Similarly, end categories of all scales had no defined widths.

\subsubsection{Comparing categories' widths from different scales}

The thermal continuum ranges covered by sensation categories were almost similar in summer and slightly different in winter as observed in Figure 2 and Figure 3 respectively. In both seasons, (neutral) category was shifted to the cool side of the continuum, whereas (comfortable) was almost centred on the continuum centre (i.e. zero point) regardless of their assumed equivalence. Although an identical 
Arabic phrase was used for both (cool) and (too cool), they had noticeably different widths in both seasons. This indicates that translation is not the only factor that determines categories' widths. Considering Nicol scale, (neutral) and (comfortable) sensations were preferred for the investigated students as they contained the centre of (no change) category in both seasons.

\subsection{Middle categories' shift from the thermal continuum centre}

The distances between the thermal continuum centre (i.e. zero point) and the centres of (neutral) and (comfortable) categories were determined. Accordingly, the behaviour of Bedford scale in both seasons seems to be relatively better owing to the closeness between the median sensation (i.e. zero point) and the centre of (comfortable) category as demonstrated in Figure 2 and Figure 3. The reason is possibly related to the used phrase that emphasised the absence of (cool) or (warm) sensations. Besides, it seems that Bedford scale exhibited a better response to the season change. This is because the centre of its middle category moved from the warm side in summer to the cool side in winter. Additionally, the spread of air conditioning systems in Omani buildings $[41,42]$ may have an influence on the investigated students as (neutral) was shifted to the cool side of the continuum in both seasons. Supporting this influence is the shift of (no change) preference to the cool side of the continuum. It may worth mentioning that the literal translation of the phrase used for (neutral) means (moderate) or (mild).

\subsection{Categories' symmetry}

With respect to the middle category centre, the categories of ASHRAE scale seem to be more symmetrical compared with those of Bedford scale as observed in Figure 2 and Figure 3. The general asymmetry of the Bedford scale may be related to integrating (comfort) in its central categories; it is possible that the students found it difficult to feel comfortable while feeling warm as in (comfortably warm) category owing to their climatic background. It is noteworthy that the votes of (slightly warm) were almost double those of (comfortably warm) in each season. Additionally, the categories of Nicol scale were relatively symmetrical around its central category in both seasons indicating good behaviour.

\subsection{Accuracy of categories' boundaries}

To determine the accuracy of the categories' limits, it is crucial to ensure the independence of the involved data [18]. Considering the research at hand, the analysed data were truly independent as each student provided one vote in each questionnaire. The computed standard errors of summer and winter studies are presented in Table 2 and Table 3 respectively. The standard errors of Bedford 
scale categories were marginally smaller in summer, whereas those of ASHRAE scale were relatively smaller in winter. This is mainly related to the sample size and was reflected by the associated Nicol scales. Indeed, the influence of sample size on the accuracy is obvious comparing the standard errors of each scale in summer with those in winter. Likewise, the standard errors of the central categories in all scales were comparatively smaller mainly owing to the usual clustering of votes in the central categories [18].

It should be mentioned that the standard errors in both seasons were generally large. Consequently, the calculated widths of categories may be considered as approximate estimations. It is possible that these errors reflected the students' doubt in using the investigated scales, which may be reasonable considering that it was the first time for almost all of the students to answer a questionnaire.

\subsection{Stability of sensation scales}

The widths of sensation categories were different in the explored seasons as observed in Figure 2 and Figure 3. To investigate the stability of the scales' behaviour, the correlation between categories' widths in summer and winter are plotted in Figure 5. Ideally, the correlation coefficient should be unity. Nevertheless, this is highly unlikely owing to the seasonal thermal variations [18]. In ASHRAE scale, the correlation coefficient was high $(r=0.995)$; however, it was negligibly higher in Bedford scale $(r=$ 0.996). Therefore, it seems that both scales maintained their behaviour throughout the survey period.

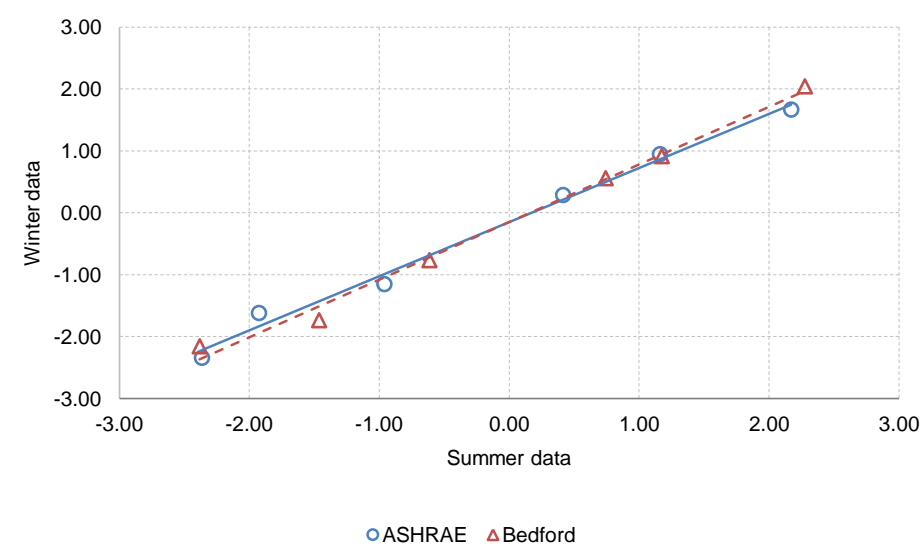

Figure 5: Comparing categories' widths of sensation scales

Besides, it is noted from Figure 5 that the plotted probits, that represent the categories upper limits, were on their assumed locations in both scales with few exceptions. In ASHRAE scale, both (cool) and (slightly cool) were shifted towards the cool side of the continuum. The exceptions in Bedford scale were (comfortable) and (comfortably warm) as the former category was shifted to the warm side as a result for the narrow width of the latter. 


\subsection{Centres of translated categories}

Based on the probits, the categories' centres were determined as presented in Table 4. It should be mentioned that the displayed centres are adjusted in order to maintain (0) as the centre of the middle categories. The computation of the centres is straightforward considering that the probits are the upper limits of the categories and it is possible to determine the centres of the end categories by two methods [18]. The first method was applied in Table 4. Considering the centres' adjustment, it is performed by moving the computed centres so the centre of the middle category coincides with the thermal continuum centre (i.e. zero point) while maintaining the standard deviation of the scale. First, the probit of the middle category is equalised to zero by subtracting or adding its absolute value. This step is then applied to the probits of the other categories. Second, the ratio between the standard deviations of the original scale (i.e. from -3 to +3 in the case of sensation scale for instance) and that resulted from the first step is determined. Third, the resulted values from the first step are multiplied by the ratio from the second step. As observed in Table 4, the actual categories' centres were different from those assumed, which confirms the change in the behaviour of the translated scales.

\begin{tabular}{|c|c|c|c|c|c|c|c|c|}
\hline \multirow{2}{*}{$\begin{array}{l}\text { Assumed } \\
\text { centres }\end{array}$} & \multicolumn{4}{|c|}{ Summer } & \multicolumn{4}{|c|}{ Winter } \\
\hline & ASHRAE & Nicol & Bedford & Nicol & Bedford & Nicol & ASHRAE & Nicol \\
\hline-3 & -2.34 & & -2.91 & & -2.66 & & -2.53 & \\
\hline-2 & -1.88 & - & -2.15 & -1.84 & -2.12 & -1.75 & -1.81 & -1.64 \\
\hline-1 & -1.17 & -0.79 & -1.19 & -1.05 & -1.32 & -1.04 & -1.12 & -0.97 \\
\hline 0 & 0.00 & 0.00 & 0.00 & 0.00 & 0.00 & 0.00 & 0.00 & 0.00 \\
\hline+1 & +1.06 & +1.06 & +0.97 & +1.03 & +0.96 & +1.06 & +1.23 & +1.06 \\
\hline+2 & +1.94 & +2.13 & +1.80 & +1.89 & +1.82 & +1.93 & +2.04 & +2.00 \\
\hline+3 & +2.71 & & +2.67 & & +2.78 & & +2.83 & \\
\hline
\end{tabular}

\section{Conclusion}

It is widely assumed that translating thermal scales maintain the characteristics of the original (English) scales. To investigate this assumption, the behaviour of Arabic translations of ASHRAE, Bedford, and Nicol scales was explored in this paper by applying the successive categories method. The translated scales were integrated into questionnaires that were distributed among female high school students in Muscat, Sultanate of Oman. The findings revealed that:

- The categories had irregular widths and the middle sensation categories were the widest indicating wide ranges of (neutral) and (comfortable) temperatures for the investigated students

- (Neutral) and (comfortable) categories covered different ranges on the thermal continuum despite their assumed equivalence with the former shifted to the cool side and the latter centred on the continuum centre 
- ASHRAE scale exhibited better symmetry around (neutral) category and Bedford scale exhibited a better seasonal response

- The shift of (neutral) and (no change) categories to the cool side of the thermal continuum may indicate the influence of the air conditioning systems on the investigated students

- Nicol scale had roughly equal width of categories and thus were relatively symmetrical around (no change) category

- The findings confirm that categories' widths are not affected by translation only.

- The computed centres of the scales' categories were different from those widely assumed

- The accuracy of the thermal comfort measurements applying regression analysis (like neutral temperature) is likely to be affected negatively.

Moreover, it was found that the deviations in the scales' behaviour were stable during the whole survey period. It should be mentioned that the calculated categories' widths should be considered as approximate estimations considering the relatively large standard errors of the categories' boundaries. Besides, the application of this investigation in female high schools is associated with some limitations. It was the first time for almost all the students to participate in a questionnaire and the majority thought that the questionnaires will be graded. This apparently may lead some of them to answer trying to please the researcher. Besides, some teachers were restricted regarding time, which created unnecessary tension on the students. Regarding the used phrases, the lack of differentiation between (cool) and (cold) in everyday Arabic vocabulary resulted in changing the covered range on the thermal continuum compared with the English version. It is recommended to conduct further explorations maintaining the implemented phrases of this study. This is because using other phrases may lead to other findings, which would be even interesting considering the lack of research regarding thermal scales' behaviour, especially in Arabic. Finally, it is worth mentioning that the successive categories method that was applied in this research has relatively a limited application in thermal comfort studies. However, it is useful in revealing the behaviour of thermal scales without the need to apply the free positioning task which is usually used to study the scales' behaviour. This has the advantage of reducing the questionnaires' size, which is usually reflected in an increased participation rate and, expectedly, increasing results' accuracy. 


\section{Acknowledgements}

The authors thank Sultan Qaboos University (SQU) for the generous financial funding of the PhD study of the first author. They also thank the Ministry of Education in the Sultanate of Oman for their support and the investigated schools for their participation.

Declaration of interest: None.

Funding: This research did not receive any specific grant from funding agencies in the public, commercial, or not-for-profit sectors.

\section{References}

[1] M.K. Nematchoua, R. Tchinda, J.A. Orosa, Thermal comfort and energy consumption in modern versus traditional buildings in Cameroon: A questionnaire-based statistical study, Appl. Energy. 114 (2014) 687-699. doi:10.1016/j.apenergy.2013.10.036.

[2] L. Yang, H. Yan, J.C. Lam, Thermal comfort and building energy consumption implications - A review, Appl. Energy. 115 (2014) 164-173. doi:10.1016/J.APENERGY.2013.10.062.

[3] H. Al-Khatri, M.B. Gadi, Using a New Programme to Predict Thermal Comfort as a Base to Design Energy Efficient Buildings, Int. J. Students' Res. Technol. Manag. 2 (2014) 172-177.

[4] M. Schweiker, X. Fuchs, S. Becker, M. Shukuya, M. Dovjak, M. Hawighorst, J. Kolarik, Challenging the assumptions for thermal sensation scales, Build. Res. Inf. 45 (2017) 572-589. doi:10.1080/09613218.2016.1183185.

[5] J.-Y. Lee, E.A. Stone, H. Wakabayashi, Y. Tochihara, Issues in combining the categorical and visual analog scale for the assessment of perceived thermal sensation: Methodological and conceptual considerations, Appl. Ergon. 41 (2010) 282-290. doi:10.1016/J.APERGO.2009.07.007.

[6] F. Nicol, M. Humphreys, S. Roaf, Adaptive thermal comfort: Principles and practice, 1st ed., Routledge, Oxon, 2012.

[7] M.A. Humphreys, M. Hancock, Do people like to feel 'neutral'?: Exploring the variation of the desired thermal sensation on the ASHRAE scale, Energy Build. 39 (2007) 867-874. doi:10.1016/J.ENBUILD.2007.02.014.

[8] A. Pitts, The language and semantics of thermal comfort, in: Wind. Conf. Comf. Energy Use Build., NCEUB (Network for Comfort and Energy Use in Buildings), Windsor, 2006: pp. 1-7.

[9] A.K. Mishra, M. Ramgopal, Field studies on human thermal comfort - An overview, Build. Environ. 64 (2013) 94-106. doi:10.1016/J.BUILDENV.2013.02.015.

[10] M.K. Singh, S. Mahapatra, S.K. Atreya, Adaptive thermal comfort model for different climatic zones of North-East India, Appl. Energy. 88 (2011) 2420-2428. doi:10.1016/J.APENERGY.2011.01.019.

[11] M.A. Humphreys, "Why did the piggy bark?" Some effects of language and context on the interpretation of words used in scales of warmth and thermal preference, in: Air Cond. Low Carbon Cool. Chall., NCEUB (Network for Comfort and Energy Use in Buildings), Windsor, 2008: pp. 1-14.

[12] R. de Dear, J. Kim, C. Candido, M. Deuble, Adaptive thermal comfort in Australian school classrooms, Build. Res. Inf 43 (2015) 383-398. doi:10.1080/09613218.2015.991627.

[13] J. Wang, Z. Wang, R. de Dear, M. Luo, A. Ghahramani, B. Lin, The uncertainty of subjective thermal comfort measurement, Energy Build. 181 (2018) 38-49. doi:10.1016/J.ENBUILD.2018.09.041.

[14] H. Al-Khatri, M.B. Gadi, Collective understanding of ASHRAE thermal sensation phrases among Arab students, in: $L$. Brotas, S. Roaf, F. Nicol, M. Humphreys (Eds.), 10th Wind. Conf. - Rethink. Comf., NCEUB (Network for Comfort and Energy Use in Buildings), Windsor, 2018: pp. 357-370.

[15] N.H. Wong, S.S. Khoo, Thermal comfort in classrooms in the tropics, Energy Build. 35 (2003) 337-351. doi:10.1016/S0378-7788(02)00109-3.

[16] N.H. Wong, H. Feriadi, P.. Lim, K.. Tham, C. Sekhar, K.. Cheong, Thermal comfort evaluation of naturally ventilated public housing in Singapore, Build. Environ. 37 (2002) 1267-1277. doi:10.1016/S0360-1323(01)00103-2.

[17] H. Feriadi, N.H. Wong, Thermal comfort for naturally ventilated houses in Indonesia, Energy Build. 36 (2004) 614-626. doi:10.1016/J.ENBUILD.2004.01.011.

[18] M. Humphreys, F. Nicol, S. Roaf, Adaptive Thermal Comfort: Foundations and Analysis, 1st ed., Routledge, Oxon, 2016.

[19] B. Hamzah, Z. Gou, R. Mulyadi, S. Amin, B. Hamzah, Z. Gou, R. Mulyadi, S. Amin, Thermal Comfort Analyses of Secondary School Students in the Tropics, Buildings. 8 (2018) 1-19. doi:10.3390/buildings8040056.

[20] H.B. Rijal, T. Omori, M.A. Humphreys, F.J. Nicol, A field-comparison of thermal comfort with floor heating systems and air conditioning systems in Japanese homes, in: Wind. Conf. Count. Cost Comf. a Chang. World, NCEUB (Network for Comfort and Energy Use in Buildings), Windsor, 2014: pp. 1-9.

[21] A. Khatun, M.A. Hasib, H. Nagano, A. Taimura, Differences in reported linguistic thermal sensation between Bangla and Japanese speakers, J. Physiol. Anthropol. 36 (2017) 1-8. doi:10.1186/s40101-017-0139-5.

[22] X. Fuchs, S. Becker, K. Schakib-Ekbatan, M. Schweiker, Subgroups holding different conceptions of scales rate room temperatures differently, Build. Environ. 128 (2018) 236-247. doi:10.1016/J.BUILDENV.2017.11.034.

[23] K. Schakib-Ekbatan, S. Becker, A. Cannistraro, M. Schweiker, What do people associate with "cold" or "hot"? Qualitative analyses of the ASHRAE-scales' labels, in: L. Brotas, S. Roaf, F. Nicol, M. Humphreys (Eds.), 10th Wind. Conf. - Rethink. Comf., NCEUB (Network for Comfort and Energy Use in Buildings), 2018: pp. 371-385.

[24] S. Shahzad, J. Brennan, D. Theodossopoulos, J.K. Calautit, B.R. Hughes, Does a neutral thermal sensation determine thermal comfort?, Build. Serv. Eng. Res. Technol. 39 (2018) 183-195. doi:10.1177/0143624418754498.

[25] B. Koelblen, A. Psikuta, A. Bogdan, S. Annaheim, R.M. Rossi, Thermal sensation models: a systematic comparison, Indoor Air. 27 (2017) 680-689. doi:10.1111/ina.12329.

[26] F. Jazizadeh, F.M. Marin, B. Becerik-Gerber, A thermal preference scale for personalized comfort profile identification 
via participatory sensing, Build. Environ. 68 (2013) 140-149. doi:10.1016/J.BUILDENV.2013.06.011.
K. Parsons, Human Thermal Environments: The Effects of Hot, Moderate, and Cold Environments on Human Health, Comfort, and Performance, 3rd ed., CRC Press, Boca Raton, 2014.

[28] C. Holes, Modern Arabic: structures, functions, and varieties, 2nd ed., Georgetown University Press, Washington, D.C., 2004.

[29] I. Nam, J. Yang, D. Lee, E. Park, J.-R. Sohn, A study on the thermal comfort and clothing insulation characteristics of preschool children in Korea, Build. Environ. 92 (2015) 724-733. doi:10.1016/J.BUILDENV.2015.05.041.

[30] M.C. Katafygiotou, D.K. Serghides, Indoor comfort and energy performance of buildings in relation to occupants' satisfaction: investigation in secondary schools of Cyprus, Adv. Build. Energy Res. 8 (2014) 216-240. doi:10.1080/17512549.2013.865554.

[31] H. Yan, L. Yang, Indoor thermal conditinos and thermal comfort in residential buildings during the winter in Lhasa, China, in: Wind. Conf. Count. Cost Comf. a Chang. World, NCEUB (Network for Comfort and Energy Use in Buildings), Windsor, 2014: pp. 1-19.

[32] J. Kim, R. de Dear, C. Cândido, H. Zhang, E. Arens, Gender differences in office occupant perception of indoor environmental quality (IEQ), Build. Environ. 70 (2013) 245-256. doi:10.1016/J.BUILDENV.2013.08.022.

[33] L. Schellen, M. Loomans, M. de Wit, W. van Marken Lichtenbelt, The influence of different cooling techniques and gender on thermal perception, Build. Res. Inf. 41 (2013) 330-341. doi:10.1080/09613218.2013.772002.

[34] S. Karjalainen, Thermal comfort and gender: a literature review, Indoor Air. 22 (2012) 96-109. doi:10.1111/j.16000668.2011.00747.x.

[35] S. Karjalainen, Gender differences in thermal comfort and use of thermostats in everyday thermal environments, Build. Environ. 42 (2007) 1594-1603. doi:10.1016/J.BUILDENV.2006.01.009.

[36] Z. Wang, A field study of the thermal comfort in residential buildings in Harbin, Build. Environ. 41 (2006) 1034-1039. doi:10.1016/J.BUILDENV.2005.04.020.

[37] K.C. Parsons, The effects of gender, acclimation state, the opportunity to adjust clothing and physical disability on requirements for thermal comfort, Energy Build. 34 (2002) 593-599. doi:10.1016/S0378-7788(02)00009-9.

[38] N.A. Al-Azri, Y.H. Zurigat, N.Z. Al-Rawahi, Development of bioclimatic chart for passive building design, Int. J. Sustain. Energy. 32 (2013) 713-723. doi:10.1080/14786451.2013.813026.

[39] F. Ragette, Traditional Domestic Architecture of the Arab Region, 1st ed., American Univeristy of Sharjah, Zlin, 2012.

[40] A. Konya, M. Vandenberg, Design primer for hot climates, Archimedia Press Limited, Reading, 2011.

[41] H. Al-Gharibi, Urbanisation and changing lifestyle patterns in Muscat, in: S. Nebel, A. von Richthofen (Eds.), Urban Oman Trends Perspect. Urban. Muscat Cap. Area, LIT Verlag, Zurich, 2016: pp. 73-79.

[42] N.H.A. Majid, N. Takagi, S. Hokoi, S.N.N. Ekasiwi, T. Uno, Field survey of air conditioner temperature settings in a hot, dry climate (Oman), HVAC\&R Res. 20 (2014) 751-759. doi:10.1080/10789669.2014.953845. 


\begin{tabular}{|c|c|c|c|c|c|}
\hline \multicolumn{2}{|c|}{ ASHRAE } & \multicolumn{2}{|c|}{ Bedford } & \multicolumn{2}{|c|}{ Nicol } \\
\hline English & Arabic & English & Arabic & English & Arabic \\
\hline Currently, I feel: & حاليا، أشعر بـ: & Currently, I feel: & حاليا، أشتعر بـ: & $\begin{array}{l}\text { Currently, I would } \\
\text { prefer to be: }\end{array}$ & حاليا، أريد أن أكون: \\
\hline Cold & باردة جدا & Much too cool & باردة جدا & Much warmer & أسخن كثير ا \\
\hline Cool & باردة & Too cool & باردة & A bit warmer & أسخن قليلا \\
\hline Slightly cool & باردة قليلا & Comfortably cool & باردة لكن مرتاحة & No change & لا تغيير \\
\hline Neutral & معتدلة & $\begin{array}{l}\text { Comfortable, neither } \\
\text { cool nor warm }\end{array}$ & مرتاحة لا باردة و لا & A bit cooler & أبرد قليلا \\
\hline $\begin{array}{c}\text { Slightly warm } \\
\text { Warm }\end{array}$ & ساخنة قليلا & $\begin{array}{c}\text { Comfortably warm } \\
\text { Too warm }\end{array}$ & ساخنة لكن مرتاحة & Much cooler & أبرد كثير ا \\
\hline Hot & ساخنة جدا & Much too warm & ساخنة جدا & & \\
\hline
\end{tabular}

Table 1: Arabic translations of questions and scales' categories as used in questionnaires 


\begin{tabular}{|c|c|c|c|c|c|c|}
\hline \multirow[b]{2}{*}{ Category } & \multicolumn{3}{|c|}{ ASHRAE, $N=333$} & \multicolumn{3}{|c|}{ Bedford, $N=349$} \\
\hline & Cum. Prop. & Probit & SE & Cum. Prop. & Probit & SE \\
\hline-3 & 0.009 & -2.37 & 0.173 & 0.009 & -2.38 & 0.172 \\
\hline-2 & 0.027 & -1.93 & 0.126 & 0.072 & -1.46 & 0.094 \\
\hline-1 & 0.168 & -0.96 & 0.079 & 0.269 & -0.61 & 0.070 \\
\hline 0 & 0.661 & 0.41 & 0.072 & 0.771 & 0.74 & 0.076 \\
\hline+1 & 0.877 & 1.16 & 0.093 & 0.880 & 1.17 & 0.092 \\
\hline+2 & 0.985 & 2.17 & 0.224 & 0.989 & 2.27 & 0.252 \\
\hline \multirow[t]{2}{*}{+3} & 1.000 & - & - & 1.000 & - & - \\
\hline & \multicolumn{3}{|c|}{ Nicol (ASHRAE), $\mathbf{N}=\mathbf{3 3 3}$} & \multicolumn{3}{|c|}{ Nicol (Bedford), $\mathrm{N}=349$} \\
\hline-2 & 0.000 & - & - & 0.006 & -2.53 & 0.193 \\
\hline-1 & 0.111 & -1.22 & 0.086 & 0.135 & -1.10 & 0.081 \\
\hline 0 & 0.351 & -0.38 & 0.070 & 0.507 & 0.02 & 0.067 \\
\hline+1 & 0.814 & 0.89 & 0.083 & 0.917 & 1.38 & 0.104 \\
\hline+2 & 1.000 & - & - & 1.000 & - & - \\
\hline
\end{tabular}

Table 2: Cumulative proportions, probits, and standard errors of thermal categories (summer) 


\begin{tabular}{|c|c|c|c|c|c|c|}
\hline Category & \multicolumn{3}{|c|}{ Bedford, N = 194} & \multicolumn{3}{|c|}{ ASHRAE, N = 209} \\
\hline-3 & 0.015 & -2.16 & 0.186 & 0.010 & -2.34 & 0.206 \\
\hline-2 & 0.041 & -1.74 & 0.143 & 0.053 & -1.62 & 0.130 \\
\hline-1 & 0.222 & -0.77 & 0.097 & 0.124 & -1.15 & 0.105 \\
\hline 0 & 0.711 & 0.56 & 0.098 & 0.612 & 0.29 & 0.089 \\
\hline+1 & 0.820 & 0.91 & 0.111 & 0.828 & 0.95 & 0.108 \\
\hline+2 & 0.979 & 2.04 & 0.270 & 0.952 & 1.67 & 0.171 \\
\hline \multirow[t]{2}{*}{+3} & 1.000 & - & - & 1.000 & - & - \\
\hline & \multicolumn{3}{|c|}{ Nicol (Bedford), N = 194} & \multicolumn{3}{|c|}{ Nicol (ASHRAE), N = 209} \\
\hline-2 & 0.005 & -2.57 & 0.250 & 0.005 & -2.59 & 0.248 \\
\hline-1 & 0.088 & -1.36 & 0.118 & 0.062 & -1.54 & 0.124 \\
\hline 0 & 0.448 & -0.13 & 0.090 & 0.344 & -0.40 & 0.088 \\
\hline+1 & 0.871 & 1.13 & 0.123 & 0.804 & 0.86 & 0.104 \\
\hline+2 & 1.000 & - & - & 1.000 & - & - \\
\hline
\end{tabular}

Table 3: Cumulative proportions, probits, and standard errors of thermal categories (winter) 


\begin{tabular}{|c|c|c|c|c|c|c|c|c|}
\hline \multirow{2}{*}{$\begin{array}{l}\text { Assumed } \\
\text { centres }\end{array}$} & \multicolumn{4}{|c|}{ Summer } & \multicolumn{4}{|c|}{ Winter } \\
\hline & ASHRAE & Nicol & Bedford & Nicol & Bedford & Nicol & ASHRAE & Nicol \\
\hline-3 & -2.34 & & -2.91 & & -2.66 & & -2.53 & \\
\hline-2 & -1.88 & - & -2.15 & -1.84 & -2.12 & -1.75 & -1.81 & -1.64 \\
\hline-1 & -1.17 & -0.79 & -1.19 & -1.05 & -1.32 & -1.04 & -1.12 & -0.97 \\
\hline 0 & 0.00 & 0.00 & 0.00 & 0.00 & 0.00 & 0.00 & 0.00 & 0.00 \\
\hline+1 & +1.06 & +1.06 & +0.97 & +1.03 & +0.96 & +1.06 & +1.23 & +1.06 \\
\hline+2 & +1.94 & +2.13 & +1.80 & +1.89 & +1.82 & +1.93 & +2.04 & +2.00 \\
\hline+3 & +2.71 & & +2.67 & & +2.78 & & +2.83 & \\
\hline
\end{tabular}

Table 4: Categories' centres of ASHRAE, Bedford, and Nicol scales in summer and winter studies 


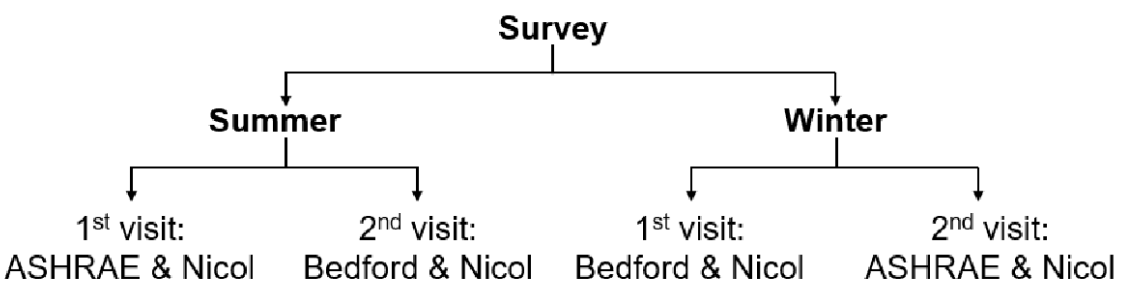

Figure 1: Sequence of questionnaires' distribution 


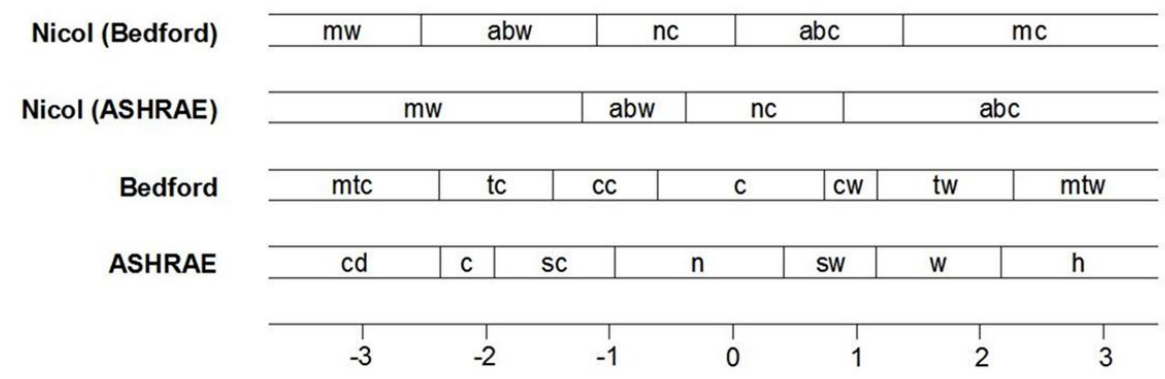

Key:

ASHRAE: $\mathrm{cd}=$ Cold $, \mathrm{cl}=\mathrm{Cool}, \mathrm{sc}=$ Slightly cool, $\mathrm{n}=$ Neutral, $\mathrm{sw}=$ Slightly warm $, \mathrm{w}=\mathrm{Warm}, \mathrm{h}=\mathrm{Hot}$ Bedford: $\mathrm{mtc}=$ Much too cool, $\mathrm{tc}=\mathrm{Too} \mathrm{cool}, \mathrm{cc}=$ Comfortably cool, $\mathrm{c}=$ Comfortable neither warm nor cool, $\mathrm{cW}=$ Comfortably warm, tw $=$ Too warm, $\mathrm{mtw}=$ Much too warm

Nicol: $\mathrm{mw}=$ Much warmer, $\mathrm{abw}=\mathrm{A}$ bit wamer, $\mathrm{nc}=$ no change, $\mathrm{abc}=\mathrm{A}$ bit cooler, $\mathrm{mc}=$ Much cooler

Figure 2: Comparing thermal categories' widths of ASHRAE, Bedford, and Nicol scales in summer 


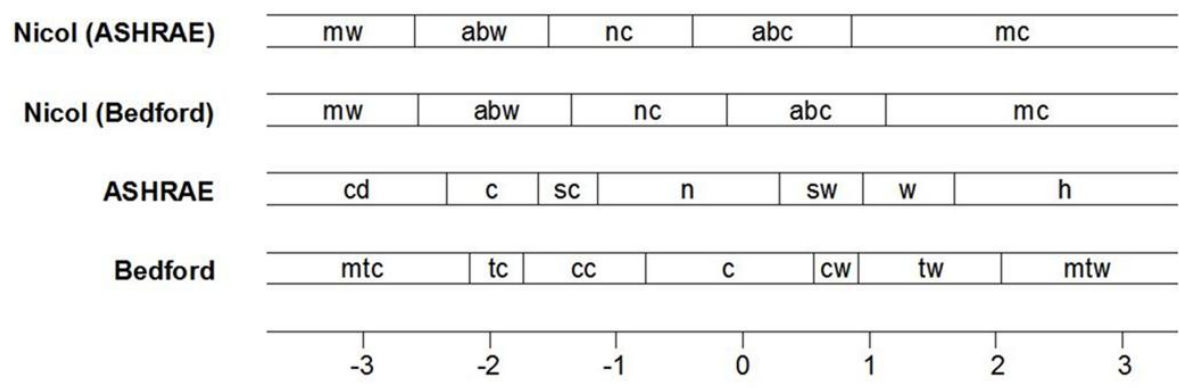

Key:

ASHRAE: $\mathrm{cd}=$ Cold $, \mathrm{cl}=\mathrm{Cool}, \mathrm{sc}=$ Slightly cool, $\mathrm{n}=$ Neutral, $\mathrm{sw}=$ Slightly warm $, \mathrm{w}=\mathrm{Warm}, \mathrm{h}=\mathrm{Hot}$ Bedford: $\mathrm{mtc}=$ Much too cool, tc $=$ Too cool, $c c=$ Comfortably cool, $\mathrm{c}=$ Comfortable neither warm nor cool, $\mathrm{cw}=$ Comfortably warm, $\mathrm{tw}=$ Too warm, $\mathrm{mtw}=$ Much too warm

Nicol: $\mathrm{mw}=$ Much wamer, $\mathrm{abw}=\mathrm{A}$ bit warmer, $\mathrm{nc}=\mathrm{no}$ change, $\mathrm{abc}=\mathrm{A}$ bit cooler, $\mathrm{mc}=$ Much cooler

Figure 3: Comparing thermal categories' widths of Bedford, ASHRAE, and Nicol scales in winter 


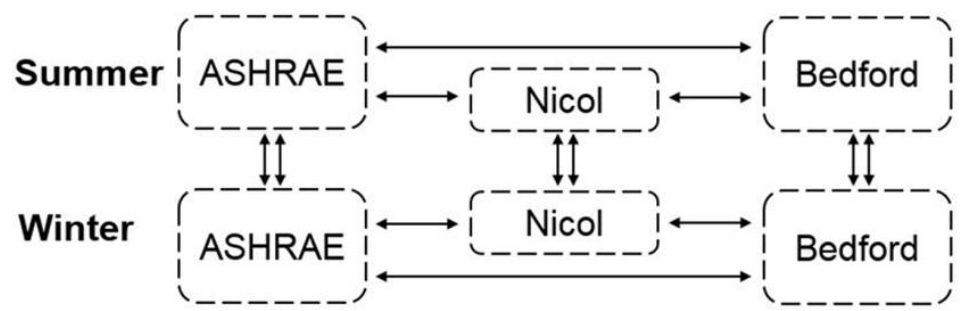

Key:

ᄃニ Level 1: same scale, same questionnaire, same survey

$\leftrightarrow$ Level 2: different scales, same or different questionnaires, same survey

$\uparrow$ Level 3: same scale, different questionnaires, same survey

Figure 4: Levels of comparing categories' widths within the thermal survey 
